\title{
Design Factors for Two-Dimensional, External-Compression Supersonic Inlets
}

\author{
John W. Slater ${ }^{1}$ \\ John H. Glenn Research Center, Cleveland, Ohio, 44145, USA
}

\begin{abstract}
Geometric and aerodynamic design factors were studied for the design of two-dimensional, external-compression inlets operating at a freestream Mach number of Mach 1.7. Computational simulations of the inlet flows were performed to obtain the inlet performance metrics consisting of the inlet flow rates, total pressure recovery, and total pressure distortion at the engine face. The key design factors identified included the external diffuser Mach number, cowl lip interior angle, bleed slot length, throat section aft centerbody slope, and subsonic diffuser length. Using the results of the Mach 1.7 inlet study, inlets were designed for Mach 1.4 and 2.0. The results provide useful insight on the significance of the design factors for the design of such inlets for commercial supersonic aircraft.
\end{abstract}

\section{Nomenclature}

$\begin{array}{ll}A & =\text { Area } \\ D & =\text { Diameter } \\ h & =\text { Height } \\ L & =\text { Length } \\ M & =\text { Mach number } \\ p & =\text { Pressure } \\ \theta & =\text { Slope of a profile or surface } \\ w & =\text { Width } \\ W & =\text { Flow rate } \\ x, y, z & =\text { Cartesian coordinates } \\ ()_{0} & =\text { Freestream property } \\ ()_{1} & =\text { Property at the cowl lip / inlet entrance station } \\ ()_{2} & =\text { Property at the engine-face station } \\ ()_{c a p} & =\text { Property associated with the reference capture area } \\ ()_{c b} & =\text { Property associated with the centerbody } \\ ()_{c w} & =\text { Property associated with the cowl } \\ ()_{p l e n} & =\text { Property associated with the bleed slot plenum } \\ ()_{s l o t} & =\text { Property associated with the bleed slot } \\ ()_{S D} & =\text { Property at station SD, start of the subsonic diffuser } \\ ()_{T H} & =\text { Property at station TH }\end{array}$

\section{I.Introduction}

The design of commercial supersonic aircraft requires an aerodynamically efficient propulsion system consisting of an inlet, engine, and nozzle integrated well with the aircraft. The focus of this paper is on the design of the inlet for efficient internal aerodynamic performance at the design supersonic cruise condition. Current commercial supersonic aircraft are being designed for flight between Mach 1.4 to just greater than Mach 2.0 [1]. The inlet for the Concorde aircraft [2] provides a useful reference for inlet design for this range of Mach numbers. The Concorde cruised at Mach 2.0 and used a two-dimensional, external-compression inlet to provide a stable terminal shock system. The two-dimensional nature of the inlet allowed forward and aft ramps that could be rotated to open the inlet throat

\footnotetext{
${ }^{1}$ Research Aerospace Engineer, Propulsion Division / Inlets and Nozzles Branch, AIAA Associate Fellow.
} 
cross-sectional area to allow passage of airflow at all operating conditions of the aircraft from take-off to cruise. The ramps also created a wide bleed slot that helped control terminal shock wave / boundary layer interactions and balance flow rates through the operating range of the aircraft. A similar inlet approach was used for the McDonnell-Douglas / Boeing F-15 aircraft [3].

This paper explores the design of two-dimensional, external-compression inlets for flight conditions of currentlyproposed commercial supersonic aircraft. For this paper, the proposed aircraft are represented by the Supersonic Technology Concept Aeroplane (STCA) as described in Ref. [4]. The STCA is a 55-ton business-class airplane powered by three turbofan engines and designed to perform trans-Atlantic flights with 8 passengers at a cruise Mach number of $M_{0}=1.4$. The STCA study included a conceptual design of a turbofan engine, which is used for the inlet design studies of this paper.

In addition to the attractive features mentioned previously, the two-dimensional inlet offers flexibility in integration of the inlet on the bottom or top surfaces of the wing, as well as, attached to the side or top of the fuselage. However, in this study, the inlet is examined isolated from the aircraft, so as to simplify the analysis problem and focus on the effect of the design factors on the internal aerodynamics. At the design supersonic cruise condition, the inlet operates at the critical condition with supersonic flow up to the cowl lip station and the terminal shock in the region of the inlet entrance. Thus, the subsonic internal flow is mostly blocked from influencing the external flow, except for a small region of subsonic spillage past the cowl lip. This approach allows examination of the effects of the internal inlet design factors, such as cowl interior centerbody angles and bleed slot length, on the inlet internal performance. The inlet performance metrics of interest include the inlet flow rates and the total pressure recovery and distortion at the engine face. Inlet wave drag is another important performance metric that is affected by the choice of inlet design factors and the drag should be included in an overall assessment of an inlet design. Proper accounting of drag would require the installation of the inlet onto an airframe and computational analysis of the entire aircraft flowfield. The approach of this paper is to focus on several key geometric factors of the internal duct of the inlet and consider the inlet operating at the supersonic cruise condition and at the critical inlet flow ratio for which the inlet interior flow has minimal effect on the exterior flow. In addition, the set of factors that are explored include some factors that are fixed such that changes to the inlet cowl exterior are minimized. Thus, the studies of this paper explore the effect of factors on the inlet interior flow and the resulting inlet performance.

Section II provides a description of the geometry modeling of the two-dimensional, external-compression inlets and identifies the geometric and aerodynamic design factors. Section III discusses the computational fluid dynamics (CFD) methods applied to solve for the steady-state flowfield and obtain the inlet aerodynamic performance metrics. Section IV discusses several studies of the design factors for Mach 1.7. The lessons of the studies for Mach 1.7 are used to design inlets for Mach 1.4 and 2.0.

\section{II.Two-Dimensional, External-Compression Inlets}

This section describes the features and lists the geometric and aerodynamic design factors for the externalcompression, two-dimensional inlets studied in this paper.

\section{A. General Features}

The general features of the two-dimensional, external-compression supersonic inlet are shown in Fig. 1. A primary feature is the external supersonic diffuser, which has a planar sidewall and a rectangular cross-section. The leading edge of the external supersonic diffuser is also referred to as the nose of the inlet. The cowl lip starts the internal ducting of the inlet, which consists of the throat section and subsonic diffuser. The downstream end of the inlet is the engine face which abuts against the circular fan face of the turbofan engine. The inlet is assumed to be symmetric with respect to a vertical plane passing through the axis of the engine face. The cowl exterior wraps about the inlet.

The $x$-coordinate is directed axially with its origin in line with the cowl lip. The $x$-axis is also the inlet axis and passes through the nose of the inlet. The $y$-axis is directed upward and passes through the cowl lip. The origin of the $y$-axis is in line with the nose. The $z$-axis completes the right-hand rule with its origin on the plane-of-symmetry.

The numeric stations 0,1 , and 2 correspond to the freestream, cowl lip or entrance, and engine face stations, respectively, and are consistent with the SAE propulsion system stations [5]. Station SD is an additional station that denotes the start of the subsonic diffuser. The following sub-sections provide details on each of the components of the inlet and the design factors that affect the design of those components.

\section{B. Freestream}

Since the inlet is considered isolated without interactions with the aircraft, the flow conditions at station 0 are those of the freestream The freestream conditions form the upstream boundary conditions to the inlet design problem and include the Mach number $\left(M_{0}\right)$, altitude $\left(h_{0}\right)$ or dynamic pressure $\left(q_{0}\right)$, and angle-of-attack $\left(\alpha_{0}\right)$. For a specified 
altitude, the Standard Atmosphere is used to find the static pressure and temperature that define the thermodynamic state of the freestream. Alternatively, the dynamic pressure can be specified and with knowledge of the Mach number, the corresponding static pressure can be calculated. With the static pressure known, the Standard Atmosphere can be used to obtain the corresponding altitude and static temperature. The angle-of-attack specifies the incidence of the inlet axis with the freestream.
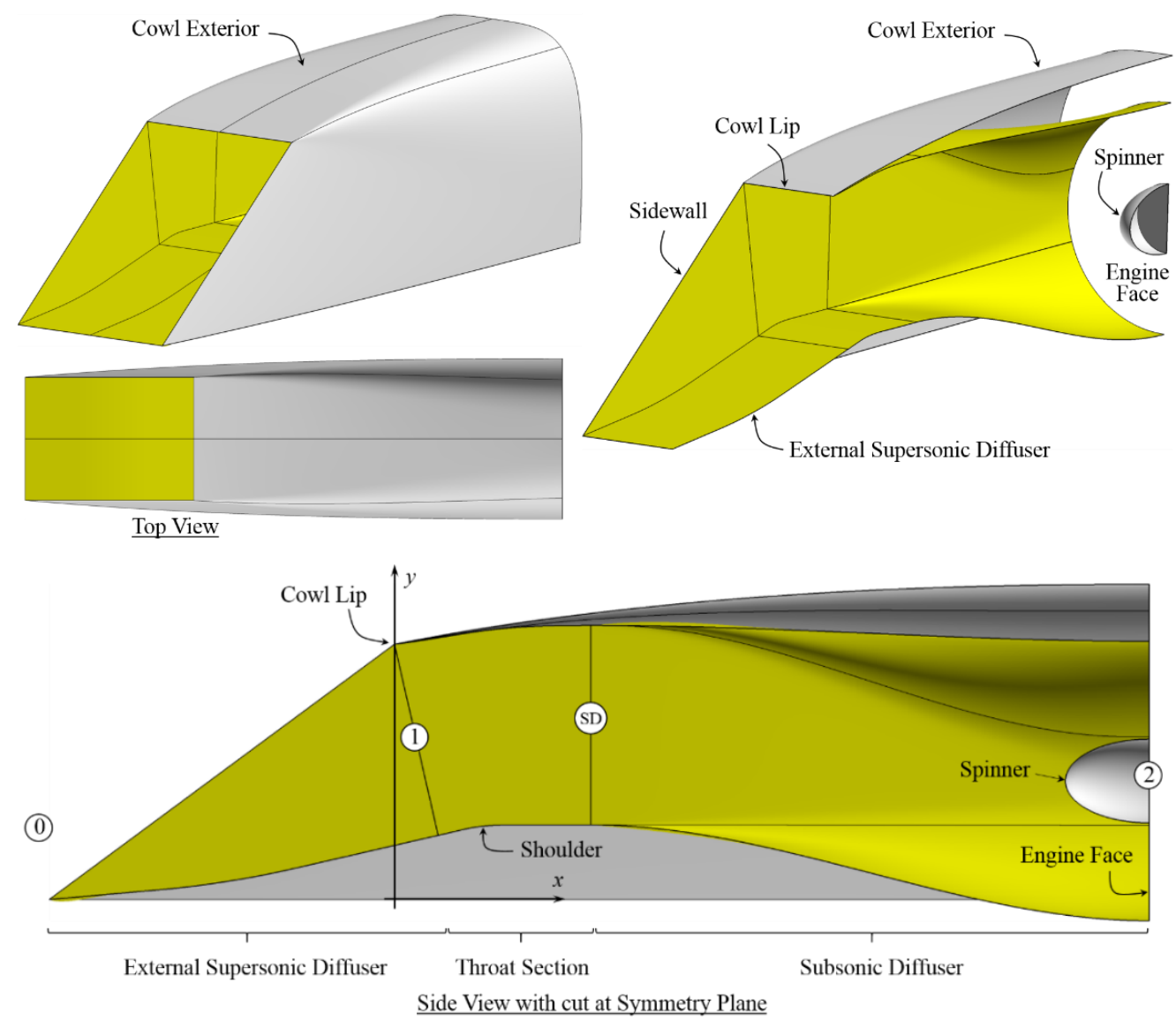

Figure 1. General features of the two-dimensional inlet.

\section{Engine Face}

The engine face forms the downstream boundary condition to the inlet design problem with the specification of the engine face geometry and the engine flow rate. The turbofan engine used for the inlet design studies is described in Ref. [4] which presents the Supersonic Technology Concept Aeroplanes (STCA). The STCA aircraft of interest here is a 55-ton business-class airplane designed to perform trans-Atlantic flights with 8 passengers at a cruise Mach number of $M_{0}=1.4$. This STCA aircraft is powered by three conceptual turbofan engines designed by NASA. The engine designs are based on publicly-available data related to the CFM International CFM56-7B engine. The engine has a single-stage fan with a smaller-diameter than that of the CFM56, but with a higher pressure ratio. The low pressure compressor was removed to compensate for the higher ram pressure and temperatures of supersonic flight. Though a mechanical layout of the system to set corresponding limits was not performed, changes to the cycle were anticipated which would enable re-use of the existing core hardware with minimal to no change, but allowing for longer operation near peak temperatures.

The engine face is modeled as an annular cross-section with a spinner at the center. The engine-face has a diameter of $D_{2}=3.625$ feet with a spinner with a hub-to-tip ratio of $D_{h u b} / D_{2}=0.3$. The spinner is modeled with an elliptic profile with an aspect ratio of length-to-diameter of 2.0. The cross-sectional area of the engine face $\left(A_{2}\right)$ is based on the annular area formed by the circular engine face and spinner hub diameter and is $A_{2}=9.3918 \mathrm{ft}^{2}$. Figure 1 shows the shapes of the engine face and spinner. The center of the engine face is positioned on the vertical plane of inlet symmetry (i.e., $z_{2}=0 \mathrm{ft}$ ). The axial placement of the engine face $\left(x_{2}\right)$ depends on the overall length of the inlet. The vertical placement of the engine face $\left(y_{2}\right)$ can vary; however, a constraint is imposed on the inlet designs of this paper to place the engine face such that the upper surface of the inlet interior forms a fairly flat profile. This results in 
reducing the angles of the forward-facing surfaces of the cowl exterior, which should result in lower wave drag. The engine-face is oriented to be perpendicular to the $x$-axis.

The engine flow rate is specified by the engine-face corrected flow rate $\left(W_{C 2}\right)$, which is set by the desired level of thrust as part of the mission of the aircraft. The values of the engine-face corrected flow rate used for the inlet designs for each freestream Mach number $\left(M_{0}\right)$ is listed in Table 1. Also, listed is the altitude $\left(h_{0}\right)$. The engine-face corrected flow rate decreases with freestream Mach number in response to limits on the engine maximum temperature. Ref. [4] only provides data for the engine of the STCA aircraft up to $M_{0}=1.4$, which is listed in Table 1 . The values of $W_{C 2}$ listed in Table 1 for $M_{0}=1.7$ and 2.0 were obtained using a linear extrapolation of the STCA engine data for $M_{0}=1.3$ and 1.4. The engine-face corrected flow rate corresponds to an engine-face mass-averaged Mach number $\left(M_{2}\right)$, which are also listed in Table 1.

Table 1. Turbofan engine-face corrected flow rates and Mach numbers.

\begin{tabular}{cccc}
\hline \hline $\boldsymbol{M}_{\boldsymbol{0}}$ & $\boldsymbol{h}_{\boldsymbol{0}}(\mathrm{ft})$ & $W_{C 2}(\mathrm{lbm} / \mathrm{s})$ & $\boldsymbol{M}_{2}$ \\
\hline 1.4 & 50000 & 413 & 0.663 \\
1.7 & 55000 & 383 & 0.581 \\
2.0 & 60000 & 353 & 0.514 \\
\hline
\end{tabular}

\section{External Supersonic Diffuser}

The external supersonic diffuser forms a compressive, supersonic flowfield in which the supersonic freestream Mach number $\left(M_{0}\right)$ is decelerated to a lower supersonic Mach number $\left(M_{E X}\right)$ at the end of the external supersonic diffuser at the upstream side of the cowl lip station 1. The external supersonic diffuser consists of one to three stages which create oblique shock waves and possibly Mach waves. The geometry of the external supersonic diffuser is formed by establishing a planar profile that is extruded in the $z$-direction. A planar sidewall is created with a leading edge defined by a line from the nose to the cowl lip.

One design factor of the external supersonic diffuser is the number of stages $\left(N_{\text {stgs }}\right)$. In this work, the values explored were $N_{\text {stgs }}=1,2$, or 3 . The first stage is always a ramp with a deflection with respect to the x-axis of $\theta_{\text {stgl }}$, which forms an oblique shock at the nose of the inlet. For $N_{\text {stgs }}=2$ and 3, additional oblique shocks are formed with discrete changes in the angles of the ramps denoted as $\theta_{s t g 2}$ and $\theta_{s t g 3}$. A second design factor is the Mach number $M_{E X}$, which for compression $M_{E X}<M_{0}$ and typical values for external compression inlets range from $1.25 \leq M_{E X} \leq 1.35$. The Oswatitsch condition [6] is used to compute the ramp angles such that the decrease in the total pressure is the same across all of the shocks. The ends of the stages are denoted by the coordinates $x_{s t g l}, x_{s t g}$, and $x_{s t g 3}$. For the case of $N_{\text {stgs }}=3$, the option exists to use a curved surface for the second stage that creates a series of compressive Mach waves that are focused on the cowl lip and form an isentropic compression. The images of Fig. 2 provide schematics of the stages and illustrate the corresponding oblique and Mach waves.
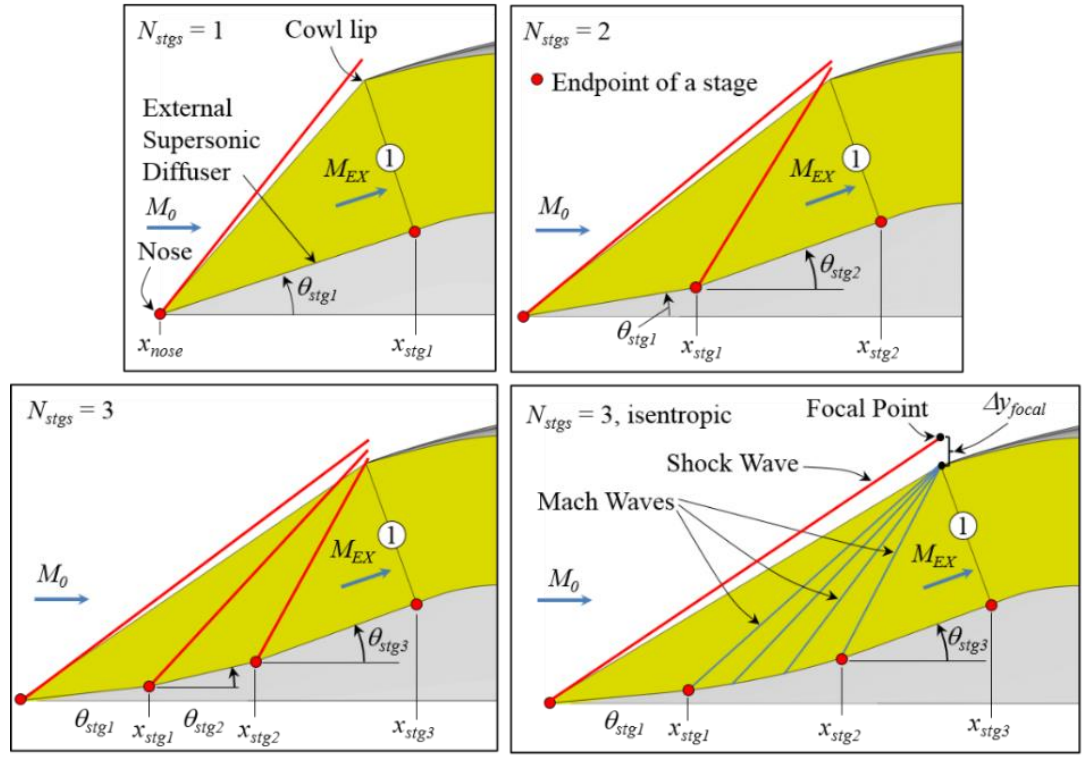

Figure 2. Geometry models for the external supersonic diffusers for the two-dimensional inlets. 
The shock and Mach waves have focal points associated with them that are placed at the $x$-coordinate of the cowl lip. At the current time, the Mach waves use the cowl lip point as their focal point. For the oblique shock waves, focal points can be specified for each shock. The placement of the focal points involve a vertical displacement $\left(\Delta y_{\text {focal }}\right)$ from the cowl lip point. This displacement is calculated using a specification of the amount of supersonic spillage $\left(W_{\text {spillage }} / W_{\text {cap }}\right)$ for the inlet. The inlets of this paper use a supersonic spillage of $W_{\text {spillage }} / W_{\text {cap }}=1 \%$ or $2 \%$. The benefit of a small level of supersonic spillage is that it places the oblique shocks a small distance ahead of the cowl lip and provides a margin against the interaction of the shocks with the cowl lip or cowl interior when the inlet is at an angleof-attack. Such interactions could degrade or destabilize the internal inlet flow.

As mentioned previously, the cross-section of the external supersonic diffuser is a rectangle. A reference area for the inlet is the capture area defined here as $A_{\text {cap }}=y_{\text {clip }} w_{\text {cap }}$. Where $y_{\text {clip }}$ is the vertical distance from the nose to the cowl lip point and $w_{c a p}$ is the width of the external supersonic diffuser. The capture flow rate $\left(W_{c a p}\right)$ is computed with the freestream conditions and the area $A_{c a p}$ and serves as the reference flow rate.

\section{E. Throat Section}

The throat section starts at station 1 and extends to the start of the subsonic diffuser at station SD. The role of the throat section is to turn the outward flow from the external supersonic diffuser toward the engine face and assure the formation of subsonic flow into the subsonic diffuser. The throat section of a two-dimensional inlet has cross-sections that are rectangular, and so, the centerbody and cowl interior through the throat section can be defined by planar profiles. The geometric design factors that define these planar profiles are shown in Fig. 3. This geometry model for the throat section is rather basic and other models can certainly be used; however, this model contains some of the basic features of a throat section.

Point $(x, y)_{c b l}$ is the start of the throat section on the centerbody and is located on the line that intersects the cowl lip and is perpendicular to the end of the external supersonic diffuser. The slope of the centerbody at station $1\left(\theta_{c b l}\right)$ is set to the slope of the last stage of the external supersonic diffuser. The profile of the centerbody through the throat section consists of three planar segments. The first segment is a line of length $L_{c b l s h}$ that starts at point $(x, y)_{c b l}$ and has a slope of $\theta_{c b l}$. The second segment is the shoulder and is formed using a non-uniform rational B-spline (NURBS) that starts at point $(x, y)_{c b s h a}$ with the slope of $\theta_{c b l}$ and ends at point $(x, y)_{c b s h b}$ with the slope of $\theta_{c b S D}$. The third segment is a line of length $L_{s h S D}$ that starts at point $(x, y)_{c b s h b}$ and ends at point $(x, y)_{c b S D}$, which is the end of the centerbody in the throat section.

The cowl interior starts at the cowl lip interior point. The profile of the cowl lip is an ellipse with the cowl lip point $(x, y)_{\text {clip }}$ being the forward-most point. The major axis of the ellipse is oriented at an angle of $\theta_{\text {clip }}$. For a supersonic inlet, the ellipse is very small to approximate a nearly sharp cowl lip leading edge.

The profile for the cowl interior through the throat section consists of two segments. The first segment starts at the downstream end of the elliptical profile of the cowl lip, which has a slope of $\theta_{\text {clip }}$, and extends to cowl station $(x, y)_{c w T H}$. The point $(x, y)_{c w T H}$ is located as the intersection point of the cowl interior profile and a vertical line that passes through point $(x, y)_{c b T H}$, defined as the point on the shoulder segment with a zero slope, or $\theta_{c b T H}=0.0$. At the point $(x, y)_{c w T H}$, the cowl interior has a slope of $\theta_{c w T H}$. The location of point $(x, y)_{c w T H}$ is fully established with the specification of the cross-sectional area at station TH $\left(A_{T H}\right)$ that is calculated using the area ratio $A_{T H} / A_{l}$. The second segment of the cowl interior starts at point $(x, y)_{c w T H}$ with slope $\theta_{c w T H}$ and ends at point $(x, y)_{c w S D}$ with slope $\theta_{c w S D}$. The location of point $(x, y)_{c w S D}$ is fully established with the specification of the cross-sectional area at station SD $\left(A_{S D}\right)$ that is calculated using the area ratio $A_{S D} / A_{l}$. The two cowl interior profile segments are formed as NURBS curves.

The throat section can accommodate a bleed slot, as shown in Fig. 3. The slot opening occurs over the length of the shoulder and replaces the shoulder surface. A bleed slot plenum is constructed below the slot with a height $\left(h_{p l e n}\right)$ and length $\left(L_{p l e n}\right)$ to form a plenum that allows the slot bleed flow to reach essentially stagnant conditions.

At the design conditions for an external-compression, supersonic inlet, the terminal shock is located in the region of station 1. On the upstream side of the terminal shock, the Mach number is $M_{E X}$ and for the two-dimensional external supersonic diffuser, the flow is uniform along the upstream side of the terminal shock. Downstream of the terminal shock, the Mach number $\left(M_{I}\right)$ is subsonic. The terminal shock may be a normal shock or a strong oblique shock. If the cowl lip interior angle is less than the flow angle, $\theta_{c l i p}<\theta_{c b l}$, and the static pressure downstream of the shock is not beyond a critical value, then a strong oblique shock can be established. The Concorde inlet [2] was able to establish a strong oblique shock, and so, reduce the loss of total pressure across the terminal shock.

Table 2 summarizes the design factors for the throat section. The lengths are specified as factors of the engineface diameter $\left(D_{2}\right)$. The sub-sections describing the inlets of the Section IV will discuss the specific values of the factors used for each of the inlets. 


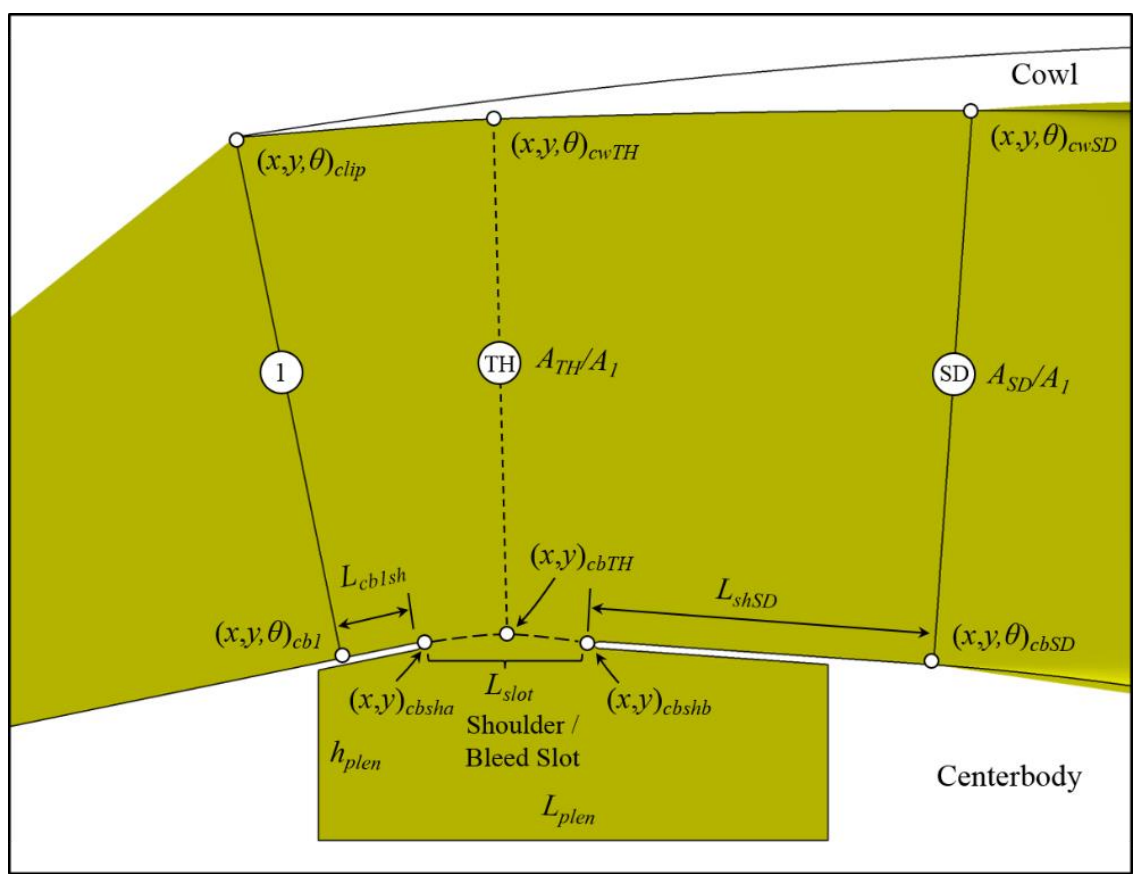

Figure 3. Geometry model for the throat section of the two-dimensional inlets.

Table 2. Design factors for the throat section.

\begin{tabular}{ll}
\hline \hline Factor & Description \\
\hline$L_{c b l s h}$ & Length of the linear segment forward of the shoulder (factor of $D_{2}$ ) \\
$L_{s l o t}$ & Axial length of the shoulder (factor of $D_{2}$ ) \\
$L_{S h S D}$ & Length of the linear segment aft of the shoulder (factor of $D_{2}$ ) \\
$\theta_{c b S D}$ & Slope of the linear segment aft of the shoulder (degrees) \\
$\theta_{c l i p}$ & Slope of the cowl lip and cowl lip interior profile (degrees) \\
$\theta_{c w T H}$ & Slope of the cowl interior at point $(x, y)_{c w T H}$ (degrees) \\
$\theta_{c w S D}$ & Slope of the cowl interior at point $(x, y)_{c w S D}($ degrees) \\
$A_{T H} / A_{1}$ & Ratio of cross-sectional areas at stations TH and 1 \\
$A_{S D} / A_{1}$ & Ratio of cross-sectional areas at stations SD and 1 \\
\hline
\end{tabular}

\section{F. Subsonic Diffuser}

The subsonic diffuser starts at station SD and ends at station 2. Figure 4 illustrates the geometry model for the subsonic diffuser for the two-dimensional inlets. The axial length of the subsonic diffuser is $L_{\text {subd }}$ and is normalized by the engine-face diameter, or $L_{\text {subd }} / D_{2}$. Over this length, the subsonic diffuser transitions in shape from a rectangular cross-section at station SD to a circular cross-section at station 2, which can be seen in Fig. 1. The coordinates $y_{S D}$ and $y_{2}$ are at the center of stations SD and 2, respectively. A two-dimensional inlet allows a vertical offset of $\left(y_{2}-\right.$ $\left.y_{S D}\right) / L_{s u b d}$ of the engine face to match the inlet up with the engine placement within the aircraft. As mentioned previously, this offset is constrained for the inlets studied in this paper so as to create inlets in which the top interior surface is mostly flat from the cowl lip to the top of the engine face.

\section{G. Supersonic Inlet Design and Analysis Tool (SUPIN)}

The design of the two-dimensional, external-compression inlets using the geometry models and design factors discussed above was facilitated through the use of the Supersonic Inlet Design and Analysis Tool (SUPIN) [7]. SUPIN is a FORTRAN 95 program that reads in a text-based input data file that provides the values of the design factors. SUPIN uses analytic, empirical, and computational methods to design the inlet and estimate the flow rates, total pressure recovery, and drag for the inlet. SUPIN generates the surfaces of the inlet and creates a Plot3D file [8] of the surface grid of the inlet. SUPIN can also automatically generate a multi-block, structured grid for a flow domain about the inlet for flow analysis using CFD methods. 


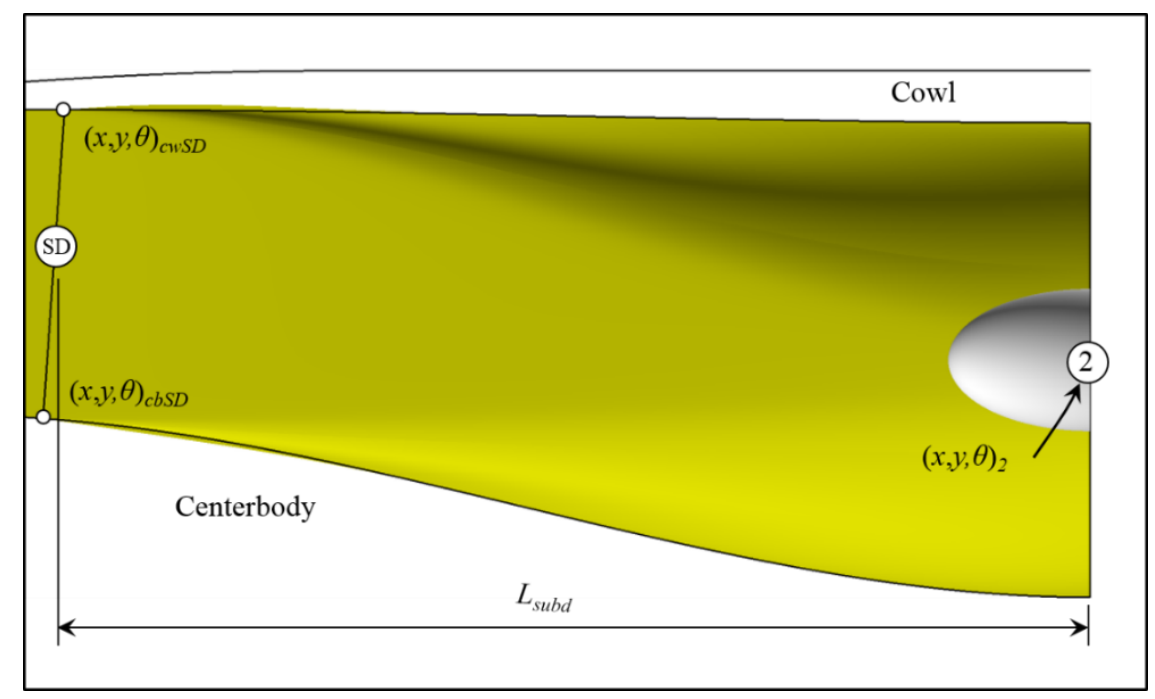

Figure 4. Geometry model for the subsonic diffuser of two-dimensional inlets.

\section{CFD Simulation Methods}

The CFD simulations were performed using the Wind-US flow solver, which is discussed in the next sub-section. Subsequent sub-sections discuss the modeling of the flow domain and boundary conditions for the two-dimensional, external-compression inlets, generation of the grid, refinement of the grids, flowfield initialization, and monitoring of the flow solution for iterative convergence.

\section{A. Wind-US Flow Solver}

The Wind-US flow solver [9] was used to solve the steady-state, Reynolds-averaged Navier-Stokes (RANS) equations for the flow properties at the grid points of a multi-block, structured grid defining a flow domain about the inlets. Wind-US used a cell-vertex, finite-volume representation for which the flow solution was located at the grid points and a finite-volume cell was formulated about the grid point. In Wind-US, the RANS equations were solved for the steady-state flow solution using an implicit time-marching algorithm with a first-order, implicit Euler method using local time-stepping from an initial flow solution. All of the simulations were performed assuming calorically-perfect air. The inviscid fluxes of the RANS equations were modeled using a second-order, upwind Roe flux-difference splitting method. The flow simulation can assume inviscid flow, as well as, viscous laminar or turbulent flow. For turbulent flow, the turbulent eddy viscosity was calculated using the two-equation Menter Shear-Stress Transport (SST) [10] turbulence model.

\section{B. Computational Flow Domain and Boundary Conditions}

Figure 5 shows the computational flow domain and boundary conditions (BC) used for the CFD simulations of the inlets. The flow domain defined the control volume in which the RANS equations were solved. The flow domain only contained the starboard half of the inlet since the inlet had geometric symmetry about the vertical plane through the center of the inlet and flow symmetry was assumed. Symmetry or reflective boundary conditions were imposed at the symmetry boundary. The internal and external surfaces of the inlet formed a portion of the boundary of the flow domain where non-slip, adiabatic viscous wall boundary conditions were imposed. The inflow and farfield boundaries of the flow domain had freestream boundary conditions imposed in which the Mach number, pressure, temperature, and angle-of-attack were specified. The inflow and farfield boundaries were positioned just upstream of the leading edge oblique shock so that the uniform freestream conditions could be imposed on those boundaries. At the downstream end of the cowl exterior, the domain had an external outflow boundary where an extrapolation boundary condition was applied for supersonic outflow.

Downstream of the engine face, a converging-diverging, outflow nozzle section was added to the flow domain to set the flow rate within the inlet. The nozzle section moved the internal outflow boundary condition downstream of the engine face, which reduced possible interference from the boundary condition on the flow at the engine face. The outflow nozzle is shown in Fig. 5. The converging-diverging portion is preceded by a portion of constant-area. The length of the outflow nozzle section was twice the diameter of the engine face, which was found sufficient for this inlet. A longer length may be required for an inlet in which significant boundary-layer separation extends into the 
engine face. The cross-sectional area of the throat was set by specifying the ratio of the diameter of the nozzle throat to the diameter of the engine-face $\left(D_{n o z} / D_{2}\right)$ and was set to form choked flow at the throat. Upstream of the nozzle throat and into the subsonic diffuser, the flow was subsonic and created the necessary back-pressure to support the terminal shock at the inlet throat section. Reducing the outflow nozzle throat area increased the back-pressure, and so, reduced the inlet flow rate. Downstream of the outflow nozzle throat, the flow was supersonic, and so, an extrapolation boundary condition could be applied at the internal outflow boundary.

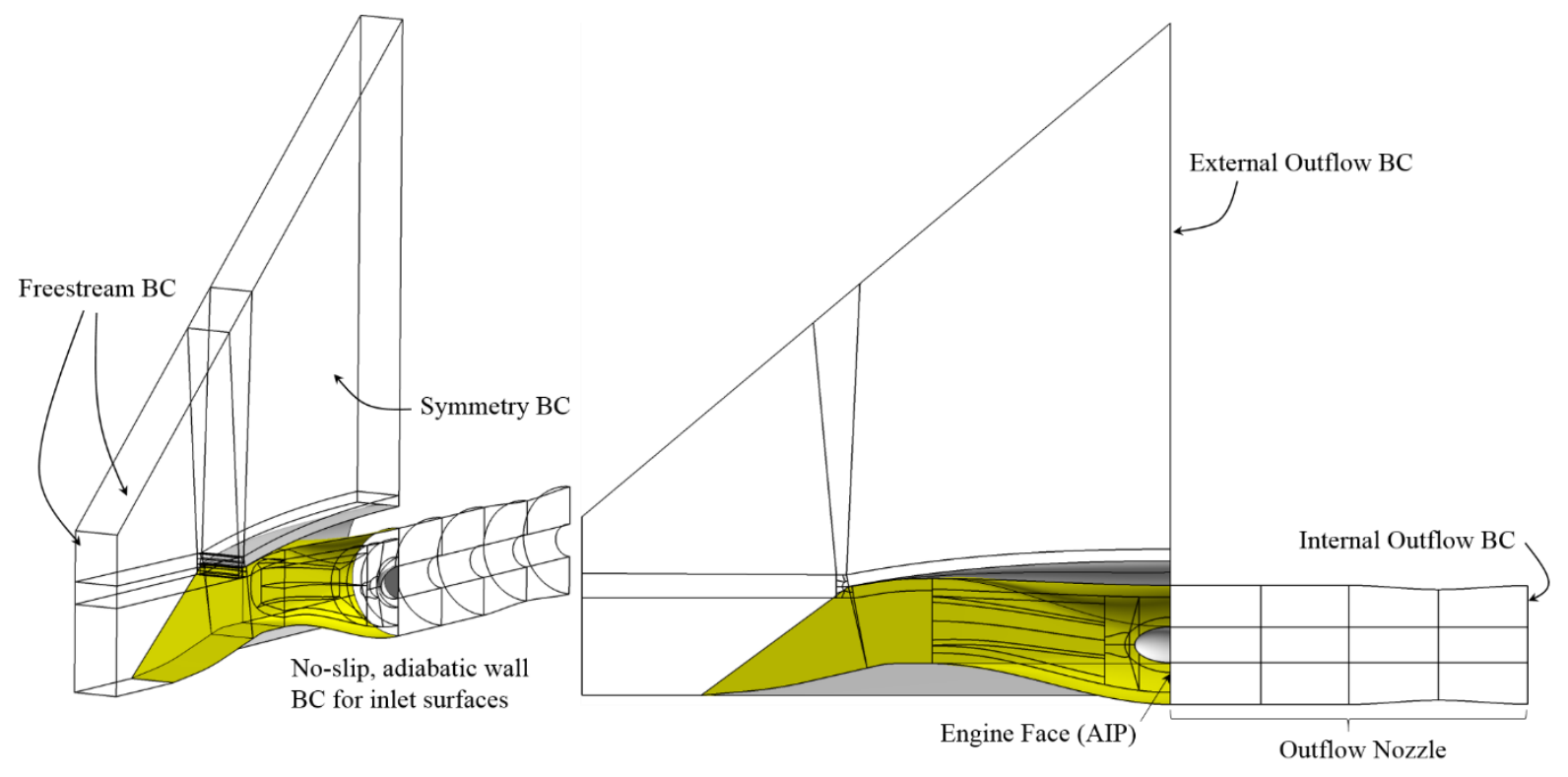

Figure 5. Flow domain and boundary conditions for the two-dimensional inlet CFD simulations.

\section{Computational Grid}

The computational grid for the flow domain was generated by dividing the flow domain into multiple blocks and generating structured grids for each block. SUPIN was used to generate the blocks and grid points using an automated process. SUPIN also created the boundary condition file for Wind-US. The inputs to the process include some factors to determine the extents of the flow domain and the resolution of the grid points. The grid resolution factors include the grid resolution of the first grid point away from the wall $\left(\Delta s_{\text {wall }}\right)$, the grid resolution within the throat section in the streamwise direction $\left(\Delta s_{x}\right)$, and the grid resolution at the symmetry boundary $\left(\Delta s_{s y m}\right)$. SUPIN then imposed these grid resolution values along the edges of the inlet geometry and flow domain to compute the required number of grid points along those edges. A grid block topology was assumed for the inlet to form the edges into faces and those faces into blocks. SUPIN generated grids along the edges, on the surfaces, and within the interior volume of each block. The interior block boundaries abutted with other block boundaries. For most blocks, the grid lines were contiguous across block boundaries, but some non-contiguous boundaries were used to facilitate the structured topology. Figures 5 and 6 show example of the flow domain with the multi-block topology. Figure 7 shows an example of the grid lines for the block faces on the symmetry boundary. The red, blue, and green colors indicate individual faces of blocks.

\section{Initial Flow Solution and Solution Monitoring}

The CFD simulations were mostly initialized with a flowfield set to the freestream conditions. However, subsonic initial conditions were imposed in the bleed slot plenum. The simulation started with the first-order form of the Roe flux-splitting method so as to damp out large initial gradients. Eventually, the second-order flux method was applied as the residuals over the iterations decreased and the boundary layers, shock waves, and subsonic inlet flow took form. At the start of the simulations, the Courant-Friedrichs-Lewy (CFL) number had a value of 0.5, but increased incrementally to a value of 2.5 as the flow solution developed. Local time stepping was used in which the local time step used was computed based on the CFL number and the local grid cell size. The iterative convergence was indicated in part by the reduction of the root-mean-square of the residuals of the conservative variables for each block. Iterative convergence was also evaluated through the monitoring of the convergence of the inlet flow rate, total pressure recovery, and total pressure distortion. The steady-state solution was considered converged when these values varied less than $0.1 \%$ of their values over $1000-2000$ iterations. 


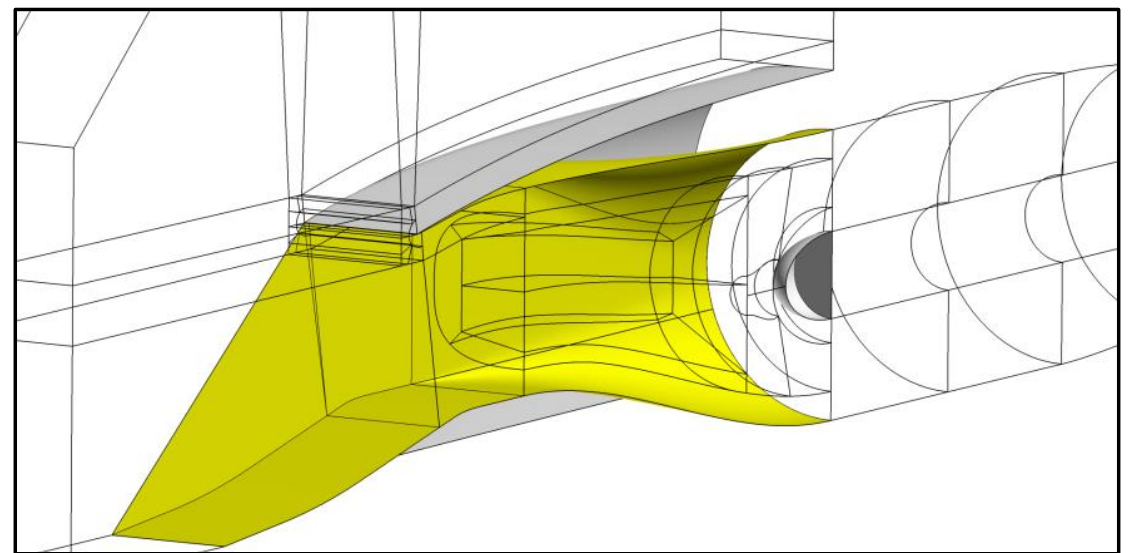

Figure 6. Structured, multi-block grid topology about the two-dimensional inlet.

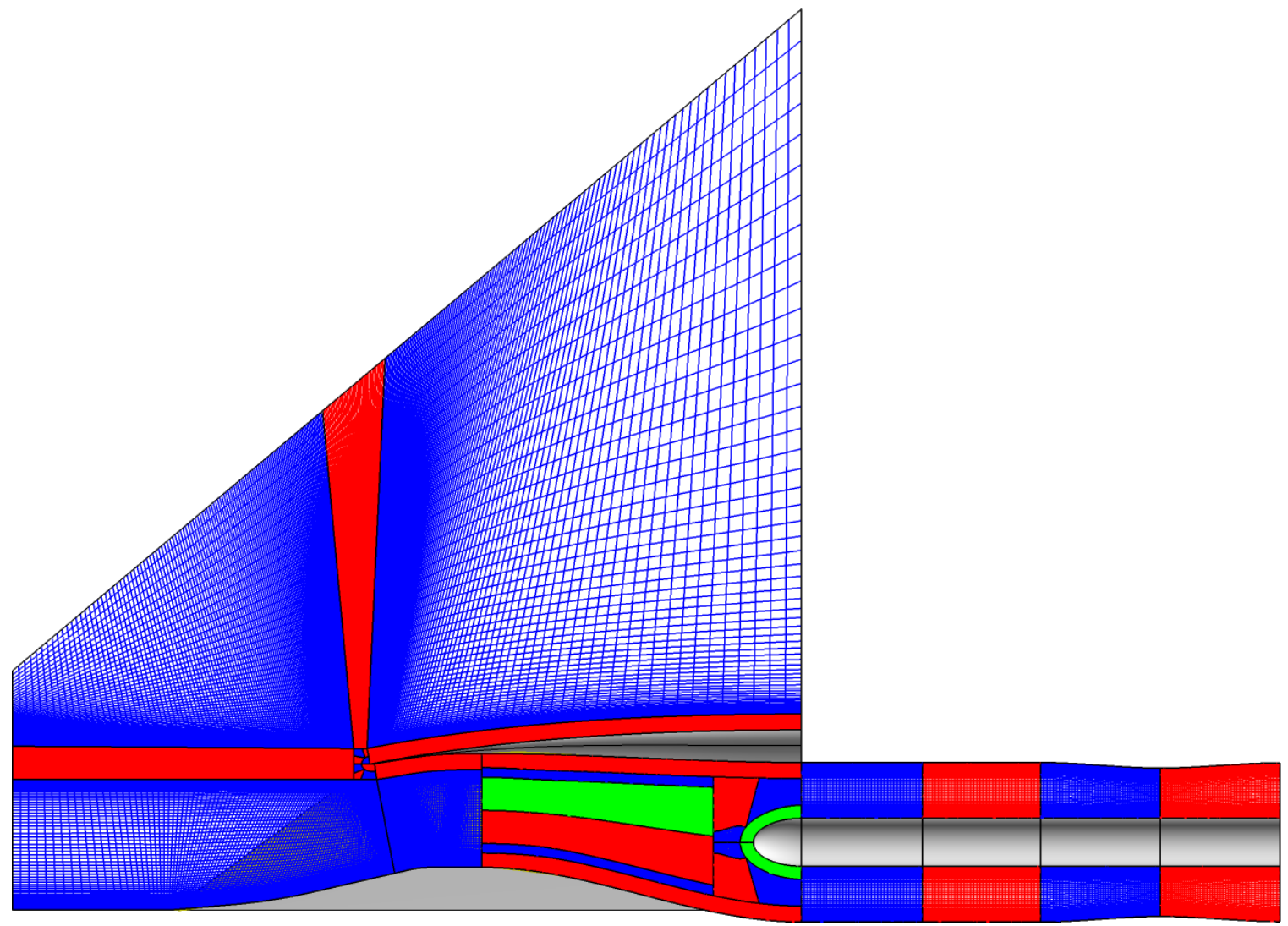

Figure 7. Structured, multi-block, computational grids on the symmetry plane for the two-dimensional inlet.

\section{E. Inlet Performance Metrics}

The flow solutions from the CFD simulations were used to obtain the aerodynamic performance metrics of the inlet. The four inlet performance metrics used to characterize the inlet included the inlet flow ratio $\left(W_{2} / W_{\text {cap }}\right)$, the inlet total pressure recovery $\left(p_{t 2} / p_{t 0}\right)$, the General Electric (GE) inlet circumferential distortion index (IDC), and the GE inlet radial distortion index $(I D R)$. The inlet flow ratio was defined as the inlet flow rate $\left(W_{2}\right)$ divided by the reference capture flow rate $\left(W_{c a p}\right)$. The inlet flow rate $\left(W_{2}\right)$ was obtained from the CFD simulation by integrating the rate of flow passing through the cross-stream grid planes of the outflow nozzle. The total pressure at the engine face $\left(p_{t 2}\right)$ was computed as the mass-average of the total pressures at the grid plane at the engine face. 
The third and fourth metrics of inlet performance were indices of the inlet circumferential (IDC) and radial (IDR) total pressure distortion at the engine face as defined by General Electric [11]. The distortion indices were defined on a standard 40-probe rake array of the Society of Automotive Engineers (SAE) Aerospace Recommended Practices (ARP) 1420 document [12]. The rake array consisted of eight radial rakes each containing five total pressure probes. In the circumferential direction the eight probes were located at a constant radius and formed a ring about the circumference of the engine face. Each ring was placed radially at the centroid of equal-area sectors. The flowfield from the CFD simulation was interpolated onto the locations of the probes to obtain the total pressure at the probe location. The IDR index is identical to the radial distortion index defined in the SAE ARP 1420, Ref. [12]. The method for computation of the IDC index for each ring can be found in Ref. [11]. The IDC indices reported in this paper were computed as the average of the $I D C$ indices computed on the two outer rings because the total pressure distortion was predominately a tip distortion.

\section{Results}

The inlet design and analysis methods were applied for the freestream and engine-face condition as listed in Table 1 for freestream Mach numbers of $M_{0}=1.4,1.7$, and 2.0. The following sub-sections presents the results for the inlet for $M_{0}=1.7$ and includes studies of the effect of the various design factors. The final two sub-sections use the lessons from the $M_{0}=1.7$ inlet studies to design inlets for $M_{0}=1.4$ and 2.0.

\section{A. Mach 1.7 Inlets: External Supersonic Diffuser}

This section discusses the design of external supersonic diffuser for the inlets for $M_{0}=1.7$ using the freestream and engine conditions of Table 1 . The first decision was the choice of the number of stages $\left(N_{s t g}\right)$ and Mach number $\left(M_{E X}\right)$ for the external supersonic diffuser. SUPIN was used to design inlets with one to three stages with $M_{E X}=1.30$. Table 3 lists the resulting total pressure ratios at the end of the external supersonic diffuser $\left(p_{t E X} / p_{t 0}\right)$ and diffuser lengths $\left(L_{E X D} / D_{2}\right)$. The row labeled "3I" indicates the inlet for which the second stage was an isentropic stage. As can be seen, as the number of stages increase, the ratios of total pressure through the stage increase and the diffuser lengths increase. It was decided to use three stages $\left(N_{s t g}=3\right)$ for the $M_{0}=1.7$ inlet with the second stage being an isentropic stage (i.e., 3I). As Table 3 shows, this choice yields the highest total pressure ratio through the external supersonic diffuser. This choice was also guided by the knowledge that the Concorde [2] inlet also used this configuration with the intent that the isentropic compression smoothed the interaction with the boundary layer better than an oblique shock. This choice also anticipated a variable-geometry ramp for the third stage of the external supersonic diffuser that would rotate about a point near the isentropic second stage.

Table 3. Properties and performance of external supersonic diffuser stages.

\begin{tabular}{ccc}
\hline \hline $\boldsymbol{N}_{\boldsymbol{s t g}}$ & $\boldsymbol{p}_{\boldsymbol{t} \boldsymbol{E X}} / \boldsymbol{p}_{\boldsymbol{t} \boldsymbol{0}}$ & $\boldsymbol{L}_{\boldsymbol{E X D}} / \boldsymbol{D}_{\boldsymbol{2}}$ \\
\hline 1 & 0.9824 & 0.7095 \\
2 & 0.9952 & 0.9201 \\
3 & 0.9979 & 0.9918 \\
$3 \mathrm{I}$ & 0.9984 & 0.9888 \\
\hline
\end{tabular}

A second decision was the choice of the Mach number at the end of the external supersonic diffuser $\left(M_{E X}\right)$. Values of $M_{E X}=1.25,1.30,1.35$, and 1.40 where explored and values of other design factors were selected to establish a baseline inlet. Table 4 lists the values of the design factors for the baseline inlet. These values were estimated to be median values of the range of possible values. The values were also established through using SUPIN and using some qualitative judgement on their effect on the shape of the inlets. The factors listed in Table 4 explicitly defined the centerbody profile. For the cowl profile, the factors $\theta_{c w T H}, \theta_{c w S D}, A_{T H} / A_{l}$, and $A_{S D} / A_{l}$ were set such that the cowl profile was smoothly varying and mostly flat from the cowl lip to the top of the engine face, as mentioned in previous sections with the intention of reducing cowl wave drag. In addition, a supersonic spillage rate of $W_{\text {spillage }} / W_{\text {cap }}=1 \%$ was specified to ensure that the external supersonic diffuser leading edge oblique shock was ahead of the cowl lip.

Table 4. Values of the design factors for the baseline Mach 1.7 inlet.

\begin{tabular}{ccccccc}
\hline \hline $\boldsymbol{\theta}_{\text {clip }}(\mathrm{deg})$ & $\boldsymbol{L}_{\boldsymbol{c} \text { blsh }} / \boldsymbol{D}_{2}$ & $\boldsymbol{L}_{\text {slot }} / \boldsymbol{D}_{\boldsymbol{2}}$ & $\boldsymbol{L}_{\text {shSD }} / \boldsymbol{D}_{2}$ & $\boldsymbol{\theta}_{\boldsymbol{c b S D}}(\mathrm{deg})$ & $\boldsymbol{L}_{\text {subd }} / \boldsymbol{D}_{\boldsymbol{2}}$ & $\left(\boldsymbol{y}_{2}-\boldsymbol{y}_{\text {SD }}\right) / \boldsymbol{L}_{\text {subd }}$ \\
\hline 4.0 & 0.10 & 0.20 & 0.40 & -4.0 & 2.2 & -0.092 \\
\hline
\end{tabular}

SUPIN created the inlets for each of the values of $M_{E X}$ and the baseline factors. Wind-US simulations were performed for each inlet with the outflow boundary condition adjusted until the engine-face Mach number was approximately $M_{2}=0.581$, as listed in Table 1 for $M_{0}=1.7$. Figure 8 shows the Mach number contours on the 
symmetry plane for each inlet. The images show the shock structure on the external supersonic diffuser consisting of the leading edge oblique shock that spills supersonic flow ahead of the cowl lip and the Mach waves of the isentropic second stage that are focused on the cowl lip. Downstream of the Mach waves, the flow has a uniform Mach number of $M_{E X}$. The terminal shock is mostly a normal shock with subsonic flow downstream of the terminal shock. The bleed slot and plenum can be seen with arrows leaving the downstream edge of the plenum to indicate the bleed flow exiting the plenum. The subsonic flow diffuses downstream of the bleed slot to decrease the Mach number as the flow approaches the spinner and engine face. Toward the bottom of the subsonic diffuser, the darker blue contours indicate regions of lower-momentum flow.

One observation of the Mach number contours of Fig. 8 is that for $M_{E X}=1.25$ and 1.30, the flow experienced a local acceleration to supersonic speeds above the bleed slot. The higher post-terminal-shock Mach numbers for these inlets made it easier for the flow to acceleration to supersonic speeds with only slight changes in the local flow areas. This seems to suggest that higher values of $M_{E X}$ are beneficial.

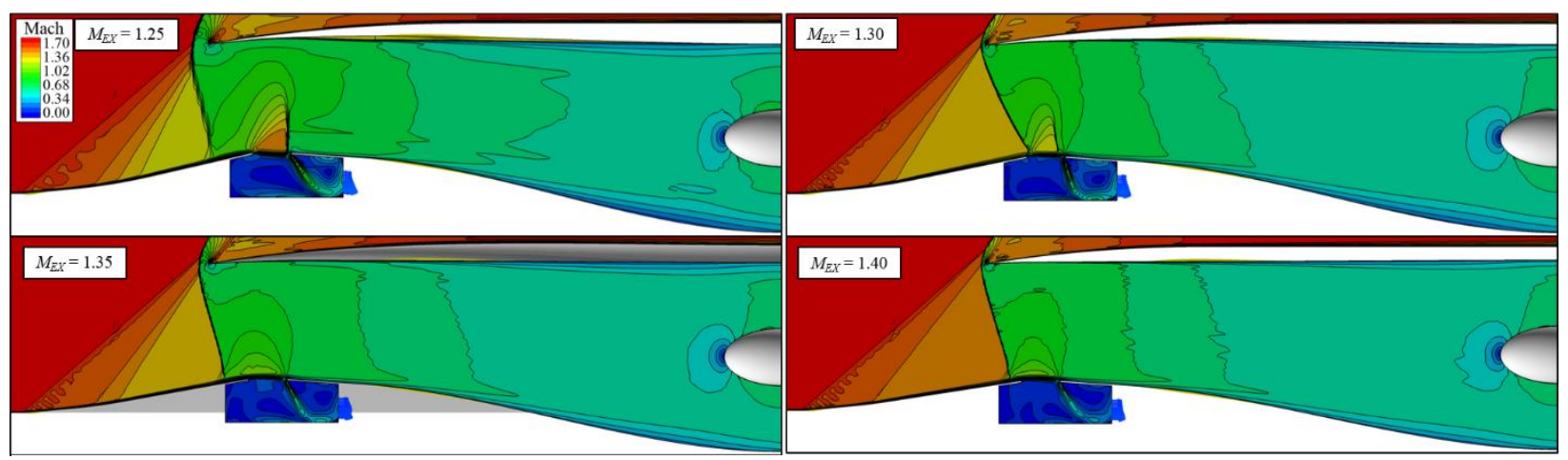

Figure 8. Mach number contours on the symmetry plane for $M_{E X}=1.25,1.30,1.35$, and 1.40 for baseline design factors for the $M_{0}=1.7$ inlets.

Table 5 lists the inlet geometric properties and performance metrics as obtained from SUPIN for these four inlets. The SUPIN results suggests that using $M_{E X}=1.25$ would be the best choice. The last two columns present the engineface Mach number $\left(M_{2}\right)$ and the total-pressure recovery $\left(p_{t 2} / p_{t 0}\right)$ as computed from the Wind-US simulations. The listing of total pressure recoveries suggests that $M_{E X}=1.30$ would provide the highest value of $p_{t 2} / p_{t 0}$, and such, this value of $M_{E X}$ was selected for further inlet studies. The MIL-E model [13] is commonly used to provide a reference for expected values of total pressure recovery. For $M_{0}=1.7$, the MIL-E model indicates a value of $p_{t 2} / p_{t 0}=0.9489$. Thus, the value of $p_{t 2} / p_{t 0}=0.9659$ is well above the MIL-E model.

Table 5. Properties and performance of external supersonic diffuser stages.

\begin{tabular}{|c|c|c|c|c|c|c|c|c|}
\hline$M_{E X}$ & $\theta_{c b 1}$ & $L_{E X D} / D_{2}$ & $A_{0} / A_{I}$ & $M_{1}$ & $\left(p_{t l} / p_{t 0}\right)_{\text {SUPIN }}$ & $\left(p_{t 2} / p_{t 0}\right)_{\text {SUPIN }}$ & $\left(M_{2}\right)_{\mathrm{CFD}}$ & $\left(\bar{l}_{t 2} / p_{t 0}\right)_{\mathrm{CFD}}$ \\
\hline 1.25 & 12.938 & 0.9965 & 1.276 & 0.8126 & 0.9855 & 0.9786 & 0.5794 & 0.9552 \\
\hline 1.30 & 11.600 & 0.9978 & 1.252 & 0.7860 & 0.9778 & 0.9710 & 0.5787 & 0.9659 \\
\hline 1.35 & 10.211 & 0.9682 & 1.226 & 0.7618 & 0.9682 & 0.9682 & 0.5783 & 0.9550 \\
\hline 1.40 & 8.785 & 0.9566 & 1.198 & 0.7397 & 0.9568 & 0.9519 & 0.5782 & 0.9474 \\
\hline
\end{tabular}

\section{B. Mach 1.7 Inlets: Grid Convergence}

A check of the grid convergence was performed for the baseline inlet with $M_{E X}=1.30$. Grids A, B, and C were generated and Table 6 lists the grid resolution values $\left(\Delta s_{x}\right.$ and $\left.\Delta s_{s y m}\right)$ in the axial and cross-stream directions, respectively. The column of $\Delta s_{E Q}$ values are the root-mean-square values of the grid resolution. The column of $h_{n}$ values is a normalized value of $\Delta s_{E Q}$ with $h_{n}=1.0$ being for the finest grid. The columns labeled $N_{x}, N_{\mathrm{r}}$, and $N_{c}$ indicate the number of grid points in the axial, radial or vertical, and cross-stream directions, respectively, along the length of the inlet. The last three columns list the inlet performance metrics from the Wind-US simulations for each grid. The Wind-US simulations on grids A111, B111, and C111 were formed using every other grid point of the grids A000, B000, and C000, respectively.

The standard deviation expressed as a percentage of the mean values of the performance metrics $p_{t 2} / p_{t 0}, I D C$, and IDR on grids A000, B000, and C000 were $0.012 \%, 2.084 \%$, and $1.348 \%$, respectively. These values can represent the uncertainty of the performance metrics with respect to grid resolution and are probably well within other uncertainties such that either of these three level of grid resolution could be used for the inlet design studies. 
Figure 9 shows images of the Mach number contours for grid $\mathrm{C}$ on the symmetry plane and on axial planes through the inlet. The axial planes show the formation of a vortex that is generated from the interaction of the cowl shock with the sidewall and the eventual interaction with the corner. The vortex propagates downstream in the subsonic diffuser along the corner and grows slightly before mostly dissipating prior to the engine face.

Table 6. Grid convergence properties and inlet performance metrics.

\begin{tabular}{|c|c|c|c|c|c|c|c|c|c|c|}
\hline Grid & $\Delta s_{x} / D_{2}$ & $\Delta s_{s y m} / D_{2}$ & $\Delta s_{E Q} / D_{2}$ & $h_{n}$ & $N_{x}$ & $N_{r}$ & $N_{c}$ & $p_{t 2} / p_{t 0}$ & $I D C$ & IDR \\
\hline A11 & 10 & 0.060 & 0.0721 & 00( & 97 & 56 & 38 & 5 & 0512 & + \\
\hline B1 & & 040 & & 2 & 133 & 66 & 42 & & & \\
\hline C111 & 0.0200 & 030 & 0361 & 2.000 & 172 & 78 & 54 & 0.9 & 0.0 & 0.0541 \\
\hline A000 & 0.0200 & 30 & .0361 & 2.000 & 194 & 111 & 75 & 0.9664 & 0.0537 & 0.0530 \\
\hline B000 & 0.0135 & 0.020 & 0.0241 & 1.339 & 265 & 132 & 83 & 0.9665 & 0.0549 & 0.0524 \\
\hline $\mathrm{C} 000$ & 0.0100 & 0.015 & 0.0180 & 1.000 & 344 & 155 & 107 & 0.9666 & 0.0565 & 0.0513 \\
\hline
\end{tabular}
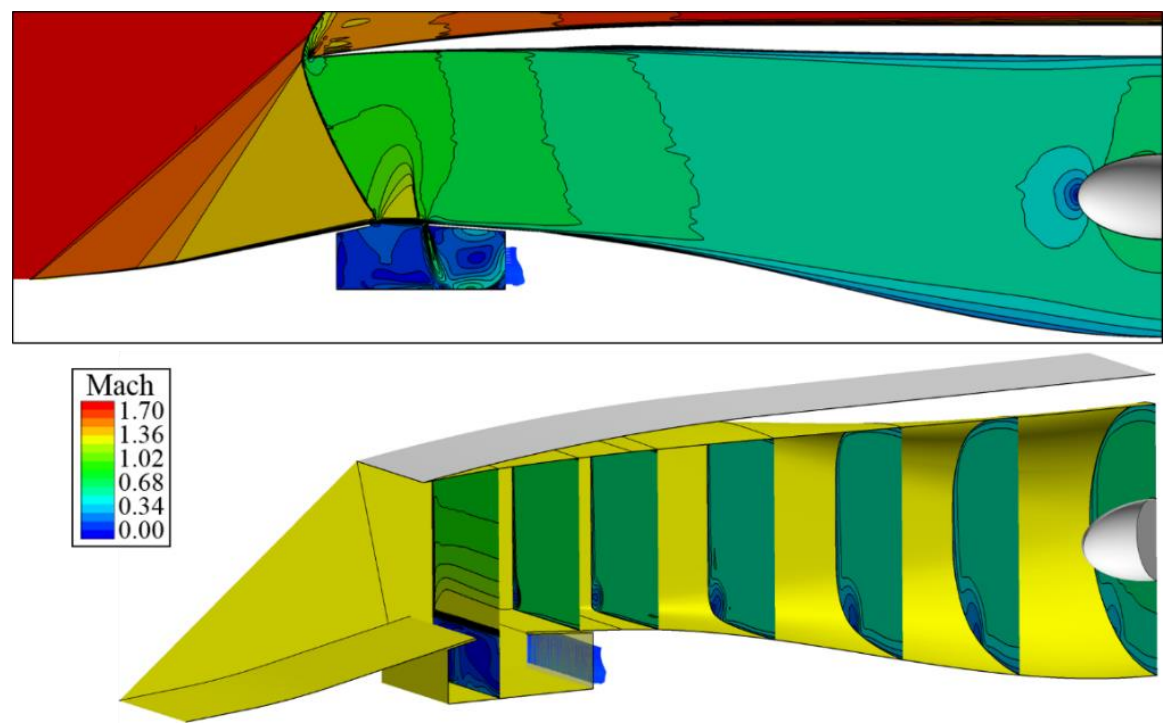

Figure 9. Mach number contours for the baseline Mach 1.7 inlet on the finest grid $\mathrm{C}$.

\section{Mach 1.7 Inlets: Bleed Rates}

The influence of the bleed rate on the inlet performance was studied for a series of inlets designed using the baseline values of the factors listed in Table 4 while the bleed rate was reduced from $2 \%$ to $0 \%$. Table 7 lists the bleed rates studied. For each bleed rate, an inlet was designed so as to capture the correct amount of engine and bleed flow. The respective capture areas $\left(A_{\text {cap }}\right)$ for the inlets are listed in Table 7 . The computational grids for the inlets were generated with the same grid resolution of Grid B. Table 7 lists the flow rates, engine-face Mach number, total pressure recovery, and distortion indices for the inlets operating near the design corrected flow rate. As the bleed rate decreases, the total pressure recovery decreases and the distortion increases. The degradation of the flow can be seen in the Mach number contours of Fig. 10. As the bleed is reduced, the low-momentum region at the bottom of the subsonic diffuser increases in size and extent. As the bleed is reduced, the spillage increases, even though the Mach number at the engine face (and so also the engine face corrected flow rate) increases. The decrease in performance of the inlet as the bleed rate decreases results in less flow to the engine.

Table 7. Inlet performance metrics with variation in the bleed rate.

\begin{tabular}{cccccccc}
\hline \hline $\boldsymbol{W}_{\text {bleed }} / \boldsymbol{W}_{\text {cap }}$ & $\boldsymbol{A}_{\text {cap }}\left(\mathrm{ft}^{2}\right)$ & $\boldsymbol{W}_{2} / \boldsymbol{W}_{\text {cap }}$ & $\boldsymbol{W}_{\text {spillage }} / \boldsymbol{W}_{\text {cap }}$ & $\boldsymbol{M}_{2}$ & $\boldsymbol{p}_{t 2} / \boldsymbol{p}_{\text {t }}$ & $\boldsymbol{I D C}$ & $\boldsymbol{I D R}$ \\
\hline $2.0 \%$ & 10.37766 & $95.90 \%$ & $2.10 \%$ & 0.57861 & 0.96653 & 0.0549 & 0.0524 \\
$1.5 \%$ & 10.22119 & $95.41 \%$ & $3.10 \%$ & 0.57930 & 0.96172 & 0.0573 & 0.0539 \\
$1.0 \%$ & 10.27176 & $94.70 \%$ & $4.31 \%$ & 0.58066 & 0.95461 & 0.0488 & 0.0636 \\
$0.5 \%$ & 10.21962 & $93.53 \%$ & $5.98 \%$ & 0.58452 & 0.94277 & 0.0760 & 0.0715 \\
$0.0 \%$ & 10.16801 & $92.94 \%$ & $7.06 \%$ & 0.58752 & 0.93792 & 0.1066 & 0.0632 \\
\hline
\end{tabular}



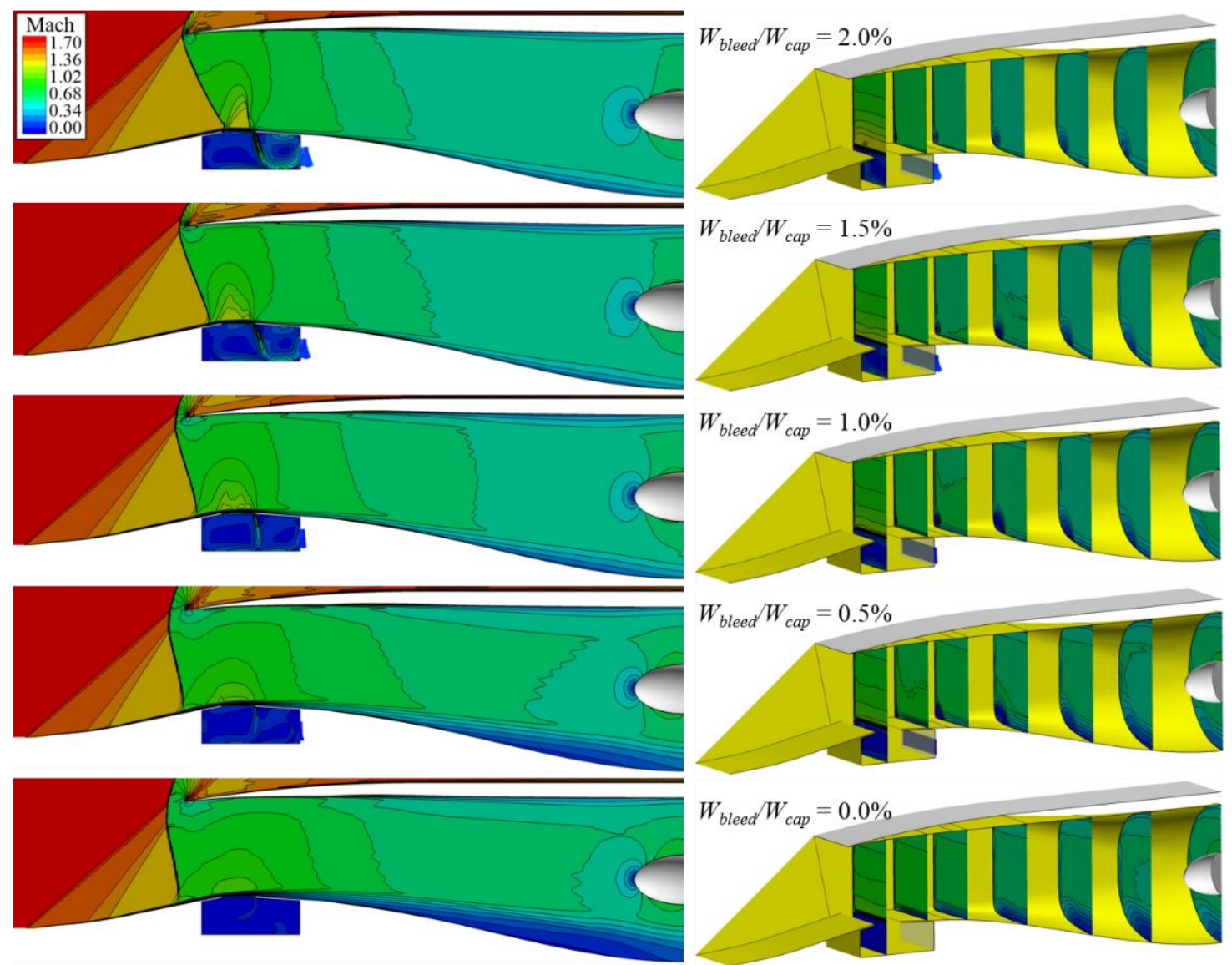

Figure 10. Mach number contours on the symmetry plane and along axial stations for inlets for $M_{0}=1.7$ with various bleed rates.

\section{Mach 1.7 Inlets: Throat Section}

An objective of the study of the throat section was to establish which of the design factors for the throat section as listed in Table 2 were most significant in improving the aerodynamic performance and to obtain an optimum set of values of those factors. Some constraints were imposed on the factors to set the bounds of the study. The first two constraints involved the specification of the profile of the throat section centerbody. The first constraint was to fix the value of the design factor for the initial length of the centerbody $\left(L_{c b l s h}\right)$ to the baseline value as listed in Table 4 , $L_{c b l s h} / D_{2}=0.1$. The design intent was to maintain the slope of the final ramp of the external supersonic diffuser a short distance into the inlet so that if the terminal shock moved downstream of station 1, a local flow expansion and acceleration does not occur on the centerbody. When the local flow accelerates to a higher Mach number, then the total pressure loss across the terminal shock increases. The second constraint was to hold fixed the overall length of the throat section. The total pressure losses through the throat section were dependent on the length, and so, by fixing the length, any changes in the inlet performance are due only to the variation in other design factors. The length was set fixed by specifying

$$
\frac{L_{c b S D}}{D_{2}}=0.6-\frac{L_{s l o t}}{D_{2}}
$$

where $L_{c b S D}$ was the length of the aft portion of the throat section centerbody. The profile of the throat section centerbody is fully specified with the specification of the length of the bleed slot $\left(L_{s l o t}\right)$ and the slope of the aft portion of the throat section $\left(\theta_{c b S D}\right)$. These two design factors were thought to be important and were varied as part of the formal study of the design factors discussed later in this section.

The design factors defining the profile for the throat section cowl interior were $\theta_{c l i p}, \theta_{c w T H}, \theta_{c w S D}, A_{T H} / A_{1}$, and $A_{S D} / A$, as listed in Table 4. The cowl lip interior angle $\left(\theta_{\text {clip }}\right)$ was thought to be an important factor and was varied as part of the formal study of the design factors discussed later in this section. The design intent of the throat section cowl 
interior profile was to create a gradual turning of the profile to the axial direction to limit any further turning of the flow. Such a cowl interior profile was shown in Fig. 9 for the baseline inlet. With the centerbody profile defined and a value set for $\theta_{c l i p}$, the factors $\theta_{c w T H}, \theta_{c w S D}, A_{T H} / A_{l}$, and $A_{S D} / A_{l}$ were adjusted such as to satisfy this constraint on the cowl interior.

The formal study of the design factors $\theta_{c l i p}, L_{s l o t}$, and $\theta_{c b S D}$ involved use of the methods of statistical design-ofexperiments (DOE). A central-composite face-centered (CCF) DOE design was used in which the three factors were varied over three levels. The axial length of the bleed slot was varied with $L_{s l o t} / D_{2}=0.1,0.2$, and 0.3 . The slope of the aft portion of the throat section centerbody was varied with $\theta_{c b S D}=0,-4$, and -8 degrees. The cowl lip interior angle was varied with $\theta_{\text {clip }}=0,4$, and 8 degrees. The flow angle at the cowl lip was equal to the slope of the final stage of the external supersonic diffuser and was shown in Table 5 to be $\theta_{c b l}=11.60$ degrees. Thus, values of $\theta_{c l i p}<$ $\theta_{c b l}$ will result in a deflection of the supersonic flow at the cowl lip.

The CCF DOE design required 15 different combinations of factors, which called for 15 inlets and Wind-US simulations. For each inlet, the engine-face outflow boundary condition was set such that the corrected flow rate matched closely to the corrected flow rate listed in Table 1 for $M_{0}=1.7$, which required that $M_{2}=0.581$. A further constraint was that the capture area of all of the inlets was set to the same capture area as the baseline inlet. The bleed rate was also specified to be $2 \%$ of the capture flow rate, and so, fixed for all of the inlets. With all of these constraints on the inlet designs, the changes in the inlet performance could be attributed only to changes in the three design factors.

The values of the design factors for each of the 15 inlets are listed in Table 8. The CFD simulations were performed and the three columns on the right-side of Table 8 list the inlet performance metrics for each inlet simulation. Figure 11 shows images of the Mach number contours on the symmetry plane for each inlet simulation. Some general observations can be seen from the images. First, the solutions with $L_{\text {slot }} / D_{2}=0.1$ indicated a supersonic flow region and small normal shock above the bleed slot, which suggests that the bleed slot was too small to pass the $2 \%$ bleed flow. Second, the solution with $\theta_{\text {clip }}=0$ degrees also showed some local acceleration of the flow to some instances of supersonic flow and the formation of a normal shock wave in the throat section. The effect of the local supersonic flow was to lower the total pressure recovery and increase distortion. This suggests that one should avoid such values for these two factors.

Table 8. Design factors and response properties of the DOE.

\begin{tabular}{ccccccc}
\hline \hline Inlet & $\boldsymbol{\theta}_{\text {clip }}(\mathrm{deg})$ & $\boldsymbol{L}_{\boldsymbol{s} \boldsymbol{l o t}} / \boldsymbol{D}_{\boldsymbol{2}}$ & $\boldsymbol{\theta}_{\boldsymbol{c b s \boldsymbol { D }}}(\mathrm{deg})$ & $\boldsymbol{p}_{\boldsymbol{t} 2} / \boldsymbol{p}_{\boldsymbol{t} \boldsymbol{0}}$ & $\boldsymbol{I D C}$ & $\boldsymbol{I D R}$ \\
\hline aaa & 8 & 0.1 & 0 & 0.9589 & 0.0568 & 0.0596 \\
aac & 8 & 0.1 & -8 & 0.9447 & 0.0719 & 0.0678 \\
abb & 8 & 0.2 & -4 & 0.9658 & 0.0470 & 0.0501 \\
aca & 8 & 0.3 & 0 & 0.9618 & 0.0548 & 0.0557 \\
acc & 8 & 0.3 & -8 & 0.9587 & 0.0531 & 0.0576 \\
bab & 4 & 0.1 & -4 & 0.9496 & 0.0535 & 0.0634 \\
bba & 4 & 0.2 & 0 & 0.9630 & 0.0573 & 0.0549 \\
bbb & 4 & 0.2 & -4 & 0.9659 & 0.0520 & 0.0538 \\
bbc & 4 & 0.2 & -8 & 0.9562 & 0.0653 & 0.0600 \\
bcb & 4 & 0.3 & -4 & 0.9616 & 0.0622 & 0.0612 \\
caa & 0 & 0.1 & 0 & 0.9493 & 0.0534 & 0.0728 \\
cac & 0 & 0.1 & -8 & 0.9367 & 0.0733 & 0.0674 \\
cbb & 0 & 0.2 & -4 & 0.9538 & 0.0520 & 0.0661 \\
cca & 0 & 0.3 & 0 & 0.9524 & 0.0476 & 0.0723 \\
ccc & 0 & 0.3 & -8 & 0.9570 & 0.0529 & 0.0603 \\
\hline
\end{tabular}

The baseline inlet (Inlet bbb in Table 8) indicated the maximum total pressure recovery. Inlet abb showed similar performance. The DesignExpert ${ }^{\circledR}$ software [14] was used to perform statistical analysis of the variations and to build a response surfaces for the each of the performance metrics listed in Table 8. A quadratic response surface was obtained for the total pressure recovery with the significant factors as shown in Eq. 2,

$$
\frac{p_{t 2}}{p_{t 0}}=0.92516+0.001013 \theta_{\text {clip }}+0.0383\left(\frac{L_{s l o t}}{D_{2}}\right)+0.002563 \theta_{c b S D}-0.008809\left(\frac{L_{\text {slot }}}{D_{2}}\right) \theta_{\text {cbSD }}-0.7877\left(\frac{L_{\text {slot }}}{D_{2}}\right)^{2}
$$

The statistical analysis indicates that $L_{\text {slot }}$ has slightly more significance than $\theta_{c l i p}$ and $\theta_{c b S D}$ and has a quadratic component that suggests that the total pressure recovery is maximized when $L_{s l o t} / D_{2} \approx 0.2$. The positive linear coefficients of $\theta_{c l i p}$ and $\theta_{c b S D}$ indicate that higher slopes increase the total pressure recovery.

A statistically-significant model was possible for $I D C$ and involved only linear terms for $L_{\text {slot }}$ and $\theta_{c b S D}$, 


$$
I D C=0.059873-0.0383\left(\frac{L_{\text {slot }}}{D_{2}}\right)-0.001165 \theta_{c b S D}
$$

A statistically-significant model was possible for $I D R$ and involved linear terms for $\theta_{\text {clip }}$ and $L_{\text {slot }}$, as shown in Eq. 4. The model for $I D R$ suggests that radial distortion is reduced when $\theta_{\text {clip }}$ is maximized and $L_{\text {slot }} / D_{2} \approx 0.2$.

$$
I D R=0.09389-0.001203 \theta_{\text {clip }}-0.2971\left(\frac{L_{\text {slot }}}{D_{2}}\right)+0.6830\left(\frac{L_{\text {slot }}}{D_{2}}\right)^{2}
$$
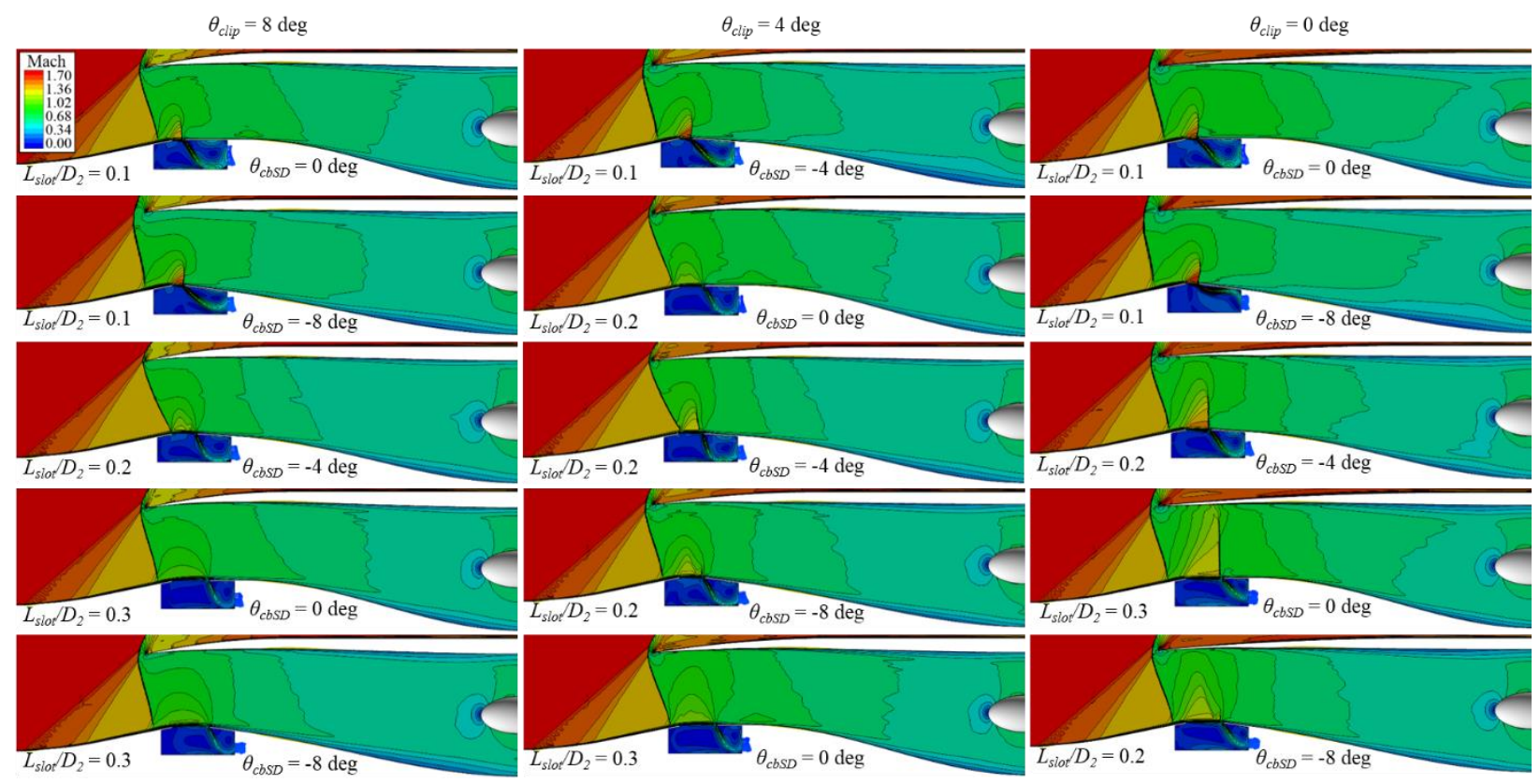

Figure 11. Mach number contours on the symmetry plane for the inlets of the DOE.

\section{E. Mach 1.7 Inlets: Optimum Configuration and Reduced Subsonic Diffuser Length}

An optimum configuration for an inlet for $M_{0}=1.7$ was formed with consideration of the results of the previous section and Eqs. 2 - 4. With regards to an optimum value for $\theta_{\text {clip }}$, the results indicated that values of $4.0 \leq \theta_{\text {clip }} \leq 8.0$ maximized $p_{t 2} / p_{t 0}$ and reduced IDR. A numerical optimization of Eq. 2 yielded an optimum value of $\theta_{\text {clip }}=7.2$ degrees to maximize $p_{t 2} / p_{t o}$. However, the cowl wave drag was not included in the optimization problem, which would suggest that a lower value of $\theta_{\text {clip }}$ would be better in reducing cowl wave drag. Thus, a value of $\theta_{\text {clip }}=6.0$ degrees was chosen as a reasonable value to represent the optimum configuration. With regards to an optimum value for $L_{\text {slot }}$, Eqs. 2 to 4 indicated an optimum value of $L_{s l o t} / D_{2}=0.22$, which was chosen as the optimum value. With regards to an optimum value for $\theta_{c b S D}$, the results indicated that higher values increased $p_{t 2} / p_{t 0}$ and reduced $I D C$. The numerical optimization of Eq. 2 yielded $\theta_{c b S D}=0.0$ degrees; however, a value of $\theta_{c b S D}=-4.0$ degrees was chosen, instead to more evenly distribute the area diffusion within the subsonic diffuser in anticipation of shortening the subsonic diffuser. Table 9 lists the final set of design factors for the optimum configuration. An inlet was generated for this optimum set of factors and the inlet performance from the CFD simulation is summarized in Table 9. The optimized inlet does yield a higher value of $p_{t 2} / p_{t 0}$ the any of the inlets of Table 8. In addition, the values of $I D C$ and $I D R$ are essentially as low as any of the inlets of Table 8 and well within acceptable limits. Thus, the optimization process seemed to work well. The Mach number contours on the symmetry plane and on axial stations along the inlet are shown in Fig. 12.

An additional two inlets were designed with the same values of the factors, except that the length of the subsonic diffuser $\left(L_{\text {subd }} / D_{2}\right)$ was decreased to explore how the inlet performance changed with a decrease in the diffuser length. Shortening the inlet is beneficial in that it results in less weight for the inlet. Table 9 lists the performance metrics and Fig. 12 shows images of the Mach number contours on the symmetry plane and on axial stations along the inlet. As the subsonic diffuser was shortened, the flow rates and total pressure recovery were unaffected. The distortion indices show a slight increase as the subsonic diffusers are shortened; however, the distortion indices are still within acceptable limits. 
Table 9. Factors and inlet performance metrics for the optimum $M_{0}=1.7$ inlet with variation in the length of the subsonic diffuser.

\begin{tabular}{|c|c|c|c|c|c|c|c|c|}
\hline$A_{\text {cap }}\left(\mathrm{ft}^{2}\right)$ & $W_{\text {bleed }} / W_{\text {cap }}$ & $\boldsymbol{\theta}_{\text {clip }}(\mathrm{deg})$ & $L_{c b 1 s h} / D_{2}$ & $L_{\text {slot }} / D_{2}$ & \multicolumn{2}{|c|}{$L_{s h S D} / D_{2}$} & \multicolumn{2}{|c|}{$\boldsymbol{\theta}_{\boldsymbol{c} \boldsymbol{c} \boldsymbol{S} \boldsymbol{D}}(\mathrm{deg})$} \\
\hline 10.3777 & $2.0 \%$ & 6.0 & 0.10 & 0.22 & & & & 0 \\
\hline$L_{\text {subd }} / D_{2}$ & \multicolumn{2}{|c|}{$\left(y_{2}-y_{S D}\right) / L_{\text {subd }}$} & $W_{2} / W_{c a p}$ & $W_{\text {spillage }} / W_{\text {cap }}$ & $M_{2}$ & $p_{t 2} / p_{t 0}$ & $I D C$ & $I D R$ \\
\hline 2.20 & \multicolumn{2}{|c|}{-0.0936} & $95.94 \%$ & $2.06 \%$ & 0.5785 & 0.9670 & 0.0484 & 0.0492 \\
\hline 2.00 & \multicolumn{2}{|c|}{-0.1025} & $95.96 \%$ & $2.04 \%$ & 0.5788 & 0.9672 & 0.0509 & 0.0491 \\
\hline 1.50 & \multicolumn{2}{|c|}{-0.1366} & $95.95 \%$ & $2.05 \%$ & 0.5802 & 0.9673 & 0.0598 & 0.0500 \\
\hline 1.25 & \multicolumn{2}{|c|}{-0.1640} & $95.72 \%$ & $2.28 \%$ & 0.5813 & 0.9658 & 0.0689 & 0.0512 \\
\hline
\end{tabular}
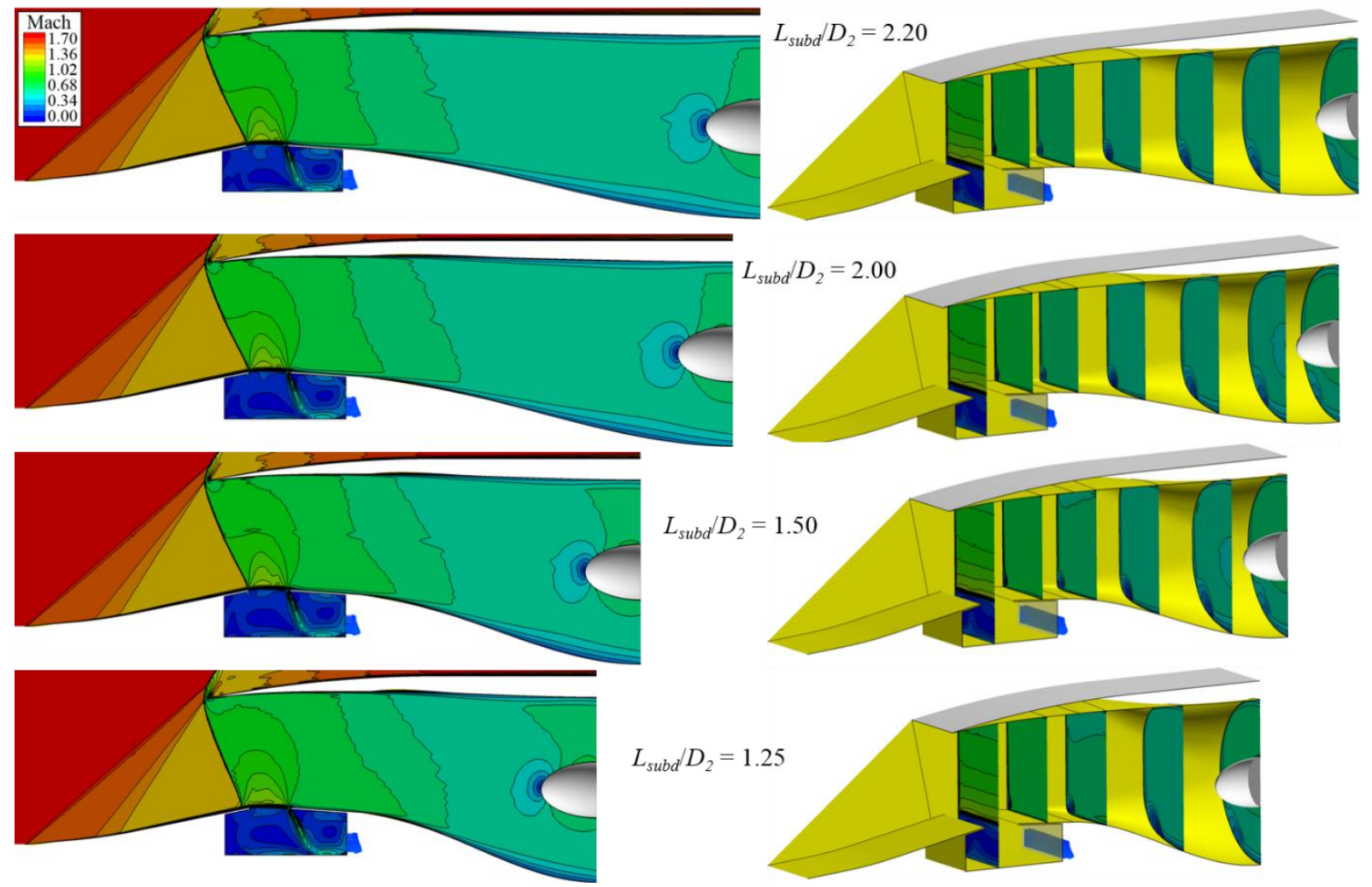

Figure 12. Mach number contours on the symmetry plane and along axial stations for the optimized inlets for $M_{0}=1.7$ with various lengths of the subsonic diffuser.

\section{F. Mach 1.4 Inlets}

The lessons of the studies for the inlets for $M_{0}=1.7$ were applied to the design of inlets for $M_{0}=1.4$. Because of the lower freestream Mach number, a supersonic compression to $M_{E X}=1.25$ was chosen which required a 4.136 degree deflection with a post-normal-terminal-shock Mach number of $M_{l}=0.813$. With such a small deflection, it was decided to only use a single ramp for the external supersonic diffuser. Table 10 lists the values of the key design factors used for the inlets. A $1 \%$ supersonic spillage was specified. The cowl lip interior angle was set at $\theta_{\text {clip }}=2.0$ degrees, which is about half of the local flow angle at the cowl lip. Two inlets were designed - one without a bleed slot and another with a bleed slot with $0.5 \%$ slot bleed specified.

Table 10 lists the performance metrics obtained from the CFD simulations for the inlets for an operating point near the design corrected flow rate of Table 1 with a corresponding engine-face Mach number of $M_{2}=0.663$. Figure 13 shows images of the Mach number contours on the symmetry plane and on axial planes through the inlets. For both inlets, additional design effort could have been performed to better match the size of the inlet capture area with the specified corrected flow rate. However, the results indicate the general level of performance at this freestream Mach number. Both inlets show good performance at the critical operating condition. The inclusion of the bleed slot does seem to slightly increase the performance, but complexity of a bleed slot would not likely be justified by such 
improvement in performance. However, the bleed slot may be of benefit for off-design inlet flow rates and subsonic operation where variable geometry may be useful to increase the throat area. Such simulations require further investigation and a useful goal would be to eliminate the need for the slot bleed. For $M_{0}=1.4$, the MIL-E model indicates a value of $p_{t 2} / p_{t 0}=0.9733$. Thus, the values of $p_{t 2} / p_{t 0}=0.9695$ and 0.9725 are close to the MIL-E model.

Table 10. Design factors and inlet performance metrics for the $M_{0}=1.4$ inlets.

\begin{tabular}{cccccccc}
\hline \hline $\boldsymbol{\theta}_{\text {clip }}(\mathrm{deg})$ & $\boldsymbol{L}_{\text {cblsh }} / \boldsymbol{D}_{2}$ & $\boldsymbol{L}_{\text {slot }} / \boldsymbol{D}_{\mathbf{2}}$ & $\boldsymbol{L}_{\text {shSD }} / \boldsymbol{D}_{2}$ & $\boldsymbol{\theta}_{\text {cbSD }}(\mathrm{deg})$ & $\boldsymbol{L}_{\text {subdl }} / \boldsymbol{D}_{2}$ & $\left(\boldsymbol{y}_{2}-\boldsymbol{y}_{\text {SD }}\right) / \boldsymbol{L}_{\text {subd }}$ \\
\hline 2.0 & 0.05 & 0.20 & 0.25 & & -4.0 & 2.0 & -0.0819 \\
\hline $\boldsymbol{W}_{\text {bleed }} / \boldsymbol{W}_{\text {cap }}$ & $\boldsymbol{W}_{2} / \boldsymbol{W}_{\text {cap }}$ & $\boldsymbol{W}_{\text {spillage }} / \boldsymbol{W}_{\text {cap }}$ & $\boldsymbol{M}_{2}$ & $\boldsymbol{p}_{\text {t2 }} / \boldsymbol{p}_{\text {to }}$ & $\boldsymbol{I D C}$ & $\boldsymbol{I D R}$ \\
\hline $0.0 \%$ & $98.73 \%$ & $1.27 \%$ & 0.6508 & 0.96952 & 0.0557 & 0.0561 \\
$0.5 \%$ & $98.15 \%$ & $1.35 \%$ & 0.6511 & 0.97248 & 0.0210 & 0.0626 \\
\hline
\end{tabular}
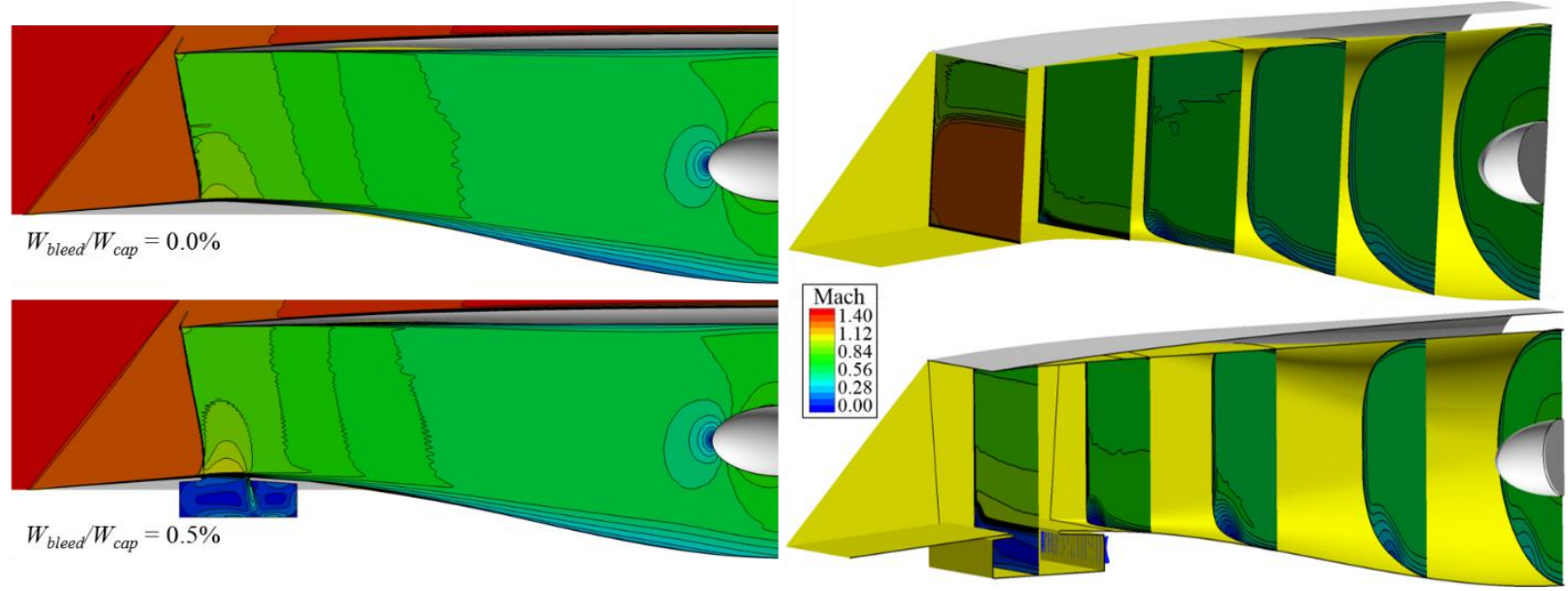

Figure 13. Mach number contours at the symmetry plane and axial stations through the inlets for $M_{0}=1.4$ with and without the slot bleed.

\section{G. Mach 2.0 Inlet}

An inlet for $M_{0}=2.0$ involved greater supersonic compression than the inlets for $M_{0}=1.4$ and 1.7. The inlet for the Concorde [2] aircraft provided some guidance for some of the design factors. An external supersonic diffuser with three stages $\left(N_{s t g}=3\right)$ was selected with the second stage being an isentropic stage, which was used for the Concorde inlet, as well as, the inlets for $M_{0}=1.7$. The supersonic compression was performed to $M_{E X}=1.35$, with the intent of creating a strong oblique terminal shock with an interaction with a bleed slot, as used with the Concorde inlet. The angle of the supersonic flow ahead of station 1 had an angle of 18.697 degrees. The post-shock Mach number was $M_{1}$ $=0.7618$. A cowl lip interior angle of $\theta_{\text {clip }}=12$ degrees was chosen to provide the deflection for the generation of the strong oblique shock at the cowl lip. A wide bleed slot, such as used with the Concorde inlet, was used to allow for a milder interaction of the terminal shock with the centerbody. The inlet was sized for 1\% supersonic spillage and 3\% slot bleed flow. Table 11 lists the values used for the design factors. Table 11 also lists the performance metrics for the inlet for a simulation that is slightly lower than the design corrected flow rate of Table 1. Figure 14 shows images of the Mach number contours on the symmetry plane and on axial planes through the inlets. The vortex originating from the lower corner of the throat section is of greater extent than that of the $M_{0}=1.7$ inlet. This likely reflects the higher pressure gradients of this higher-speed inlet. For $M_{0}=2.0$, the MIL-E model indicates a value of $p_{t 2} / p_{t 0}=$ 0.9204. Thus, the value of $p_{t 2} / p_{t 0}=0.9354$ is above the MIL-E model. As reference, the Concorde inlet was able to obtain a total pressure recovery at the critical operating points of $p_{t 2} / p_{t 0} \approx 0.96$ with $M_{E X}=1.91$ and $6 \%$ slot bleed [2]. The $I D C$ and $I D R$ distortion indices are still within acceptable limits. Further study of the design factors is needed for the $M_{0}=2.0$ inlet. 
Table 11. Design factors and inlet performance metrics for the $M_{0}=\mathbf{2 . 0}$ inlets.

\begin{tabular}{cccccccc}
\hline \hline $\boldsymbol{\theta}_{\text {clip }}(\mathrm{deg})$ & $\boldsymbol{L}_{\text {cblsh }} / \boldsymbol{D}_{2}$ & $\boldsymbol{L}_{\text {slot }} / \boldsymbol{D}_{2}$ & $\boldsymbol{L}_{\text {shSD }} / \boldsymbol{D}_{2}$ & $\boldsymbol{\theta}_{\text {cbSD }}(\mathrm{deg})$ & $\boldsymbol{L}_{\text {subdd }} / \boldsymbol{D}_{2}$ & $\left(\boldsymbol{y}_{2}-\boldsymbol{y}_{\text {SD }}\right) / \boldsymbol{L}_{\text {subd }}$ \\
\hline 12.0 & 0.10 & 0.25 & 0.35 & & -4.0 & 2.0 & -0.0896 \\
\hline $\boldsymbol{W}_{\text {bleed }} / \boldsymbol{W}_{\text {cap }}$ & $\boldsymbol{W}_{2} / \boldsymbol{W}_{\text {cap }}$ & $\boldsymbol{W}_{\text {spillage }} / \boldsymbol{W}_{\text {cap }}$ & $\boldsymbol{M}_{2}$ & $\boldsymbol{p}_{\boldsymbol{t} 2} / \boldsymbol{p}_{\text {to }}$ & $\boldsymbol{I D C}$ & $\boldsymbol{I D R}$ \\
\hline $3.0 \%$ & $94.44 \%$ & $2.56 \%$ & 0.5044 & 0.9354 & 0.0923 & 0.0442 \\
\hline
\end{tabular}
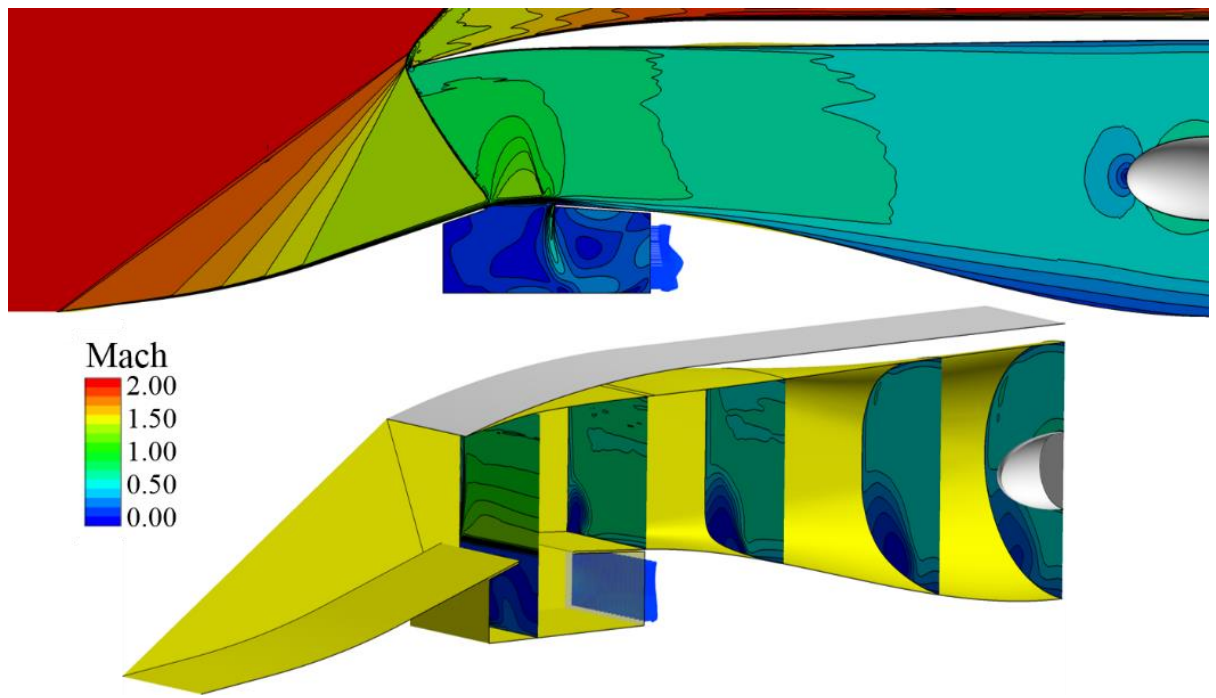

Figure 14. Mach number contours at the symmetry plane and axial stations through the inlet for $M_{0}=\mathbf{2 . 0}$ with slot bleed.

\section{Conclusion}

Design factors for two-dimensional, external-compression inlets operating at their critical design corrected flow rate for Mach 1.4, 1.7, and 2.0 were studied. The inlets featured cowl lip interior angles $\left(\theta_{\text {clip }}\right)$ lower than the local flow angle $\left(\theta_{c b l}\right)$, which likely resulted in lower cowl wave drag. However, very low cowl lip interior angles could result in a too great of reduction of the inlet streamtube, which could result in acceleration of the flow to supersonic speeds and higher total pressure losses. Reasonable values of the cowl lip interior angles are $0.50 \theta_{c b l} \leq \theta_{c l i p} \leq 0.75 \theta_{c b l}$. The use of a bleed slot was demonstrated and the length of the opening of the bleed slot $\left(L_{s l o t}\right)$ was shown to be an important factor for allowing the bleed flow to be extracted while avoiding local acceleration of the flow to supersonic speeds within the throat section. The desirable length of the bleed slot is dependent on the rate of slot bleed flow with a larger opening required as the bleed flow rate increases. A desirable slope for the aft portion of the centerbody $\left(\theta_{c b S D}\right)$ seemed to favor lower slopes that would yield a more gradual area diffusion toward the start of the subsonic diffuser and greater area diffusion toward the engine face. Further study is needed to evaluate these inlets for subcritical and subsonic operation, as well as, accounting for inlet drag.

\section{Acknowledgments}

This work was funded by the NASA Commercial Supersonic Technology (CST) Project.

\section{References}

[1] Hadhazy, A., "Supersonics Not-So-Super Emissions”, Aerospace America, October 2019.

[2] Rettie, I. H. and Lewis, W. G. E., "Design and Development of an Air Intake for a Supersonic Transport Aircraft," AIAA Journal of Aircraft, Vol. 5, No. 6, November-December, 1968, pp. 513-521. doi: 10.2514/3.43977.

[3] Imfeld, W. F., "Development Program for the F-15 Inlet," AIAA Journal of Aircraft, Vol. 13, No. 4, p. 286-291, April 1976. doi: 10.2514/3.58657. 
[4] Berton, J. J., Huff, D. L., Seidel, J. A., and Geiselhart, K. A., "Supersonic Technology Concept Aeroplanes for Environmental Studies," AIAA Paper 2020-0263, January 2020.

[5] Society of Automotive Engineering (SAE), "Aircraft Propulsion System Performance Station Designation and Nomenclature,” Aerospace Standard (AS) 755, December 1997.

[6] Oswatitsch, K., "Pressure Recovery for Missiles with Reaction Propulsion at High Supersonic Speeds (The Efficiency of Shock Diffusers)", NACA TM 1140, June 1947. (Translation of a 1944 German report).

[7] Slater, J. W., "SUPIN: A Computational Tool for Supersonic Inlet Design," AIAA Paper 2016-0532, January 2016.

[8] Walatka, P. P., Buning, P. G., Pierce, L., and Elson, P. A., "PLOT3D User's Manual,” NASA-TM-101067, March 1990.

[9] Yoder, D. A., ‘Wind-US User’s Guide: Version 3.0,’ NASA TM 2016-219078, March 2016.

[10] Menter, F. R., "Two-Equation Eddy-Viscosity Turbulence Models for Engineering Applications," AIAA Journal, Vol. 32, No. 8, 1994, pp. 1598-1605. doi: 10.2514/3.12149.

[11] Moore, M. T. “Distortion Data Analysis”, Report AFATPL-TR-72-111, February 1973.

[12] Society of Automotive Engineers (SAE), "Gas Turbine Engine Inlet Flow Distortion Guidelines," SAE ARP 1420, Rev. B, February 2002.

[13] MIL-STD-5008C, “Engines, Aircraft, Turbo-Jet, and Turbofan, Model Specifications For,” December 1965.

[14] Design Expert, Version 10, Stat-Ease, Inc., Minneapolis, MN, 2016. 